Canadian

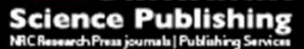

Canadian Journal of Civil Engineering Revue canadienne de génie civil

\title{
Reconsideration of the Overlap Region in Smooth Shallow Open Channel Flows
}

\begin{tabular}{|r|l|}
\hline Journal: & Canadian Journal of Civil Engineering \\
\hline Manuscript ID & cjce-2016-0333.R1 \\
\hline Manuscript Type: & Article \\
\hline Date Submitted by the Author: & 24-Nov-2016 \\
\hline Complete List of Authors: & $\begin{array}{l}\text { Heidari, Mehdi; University of Windsor, civil and environmental } \\
\text { Balachandar, Ram; Professor and Head, } \\
\text { Roussinova, Vesselina; University of Windsor, Civil and Environmental } \\
\text { engineering } \\
\text { Barron, Ron; University of Windsor, ; }\end{array}$ \\
\hline Keyword: & $\begin{array}{l}\text { fluid mech \& hydrodyn < Hydrotechnical Eng., environ fluid mechanics < } \\
\text { Engineering Mechanics, experimental research < type of paper to review }\end{array}$ \\
\hline & \\
\hline
\end{tabular}

SCHOLARONE ${ }^{m}$

Manuscripts 


\section{Reconsideration of the Overlap Region in Smooth Shallow Open Channel Flows}

MEHDI HEIDARI, Research Assistant, Civil and Environmental Engineering, University of Windsor, 401 Sunset Ave., Windsor, ON, Canada, N9B 3P4

Email:heidari1@uwindsor.ca

RAM BALACHANDAR, Professor, Civil and Environmental Engineering, University of Windsor, 401 Sunset Ave., Windsor, ON, Canada, N9B 3P4 (author for correspondence)

Phone: +1 (519) 253-3000, Ext. 3563

Fax: +1 (519) 971-3686

Email: rambala@uwindsor.ca

VESSELINA ROUSSINOVA, Assistant Professor, Mechanical, Automotive and Materials Engineering, University of Windsor, 401 Sunset Ave., Windsor, ON, Canada, N9B 3P4

Email:vtr@uwindsor.ca

RONALD M. BARRON, Professor, Mechanical, Automotive and Materials Engineering, University of Windsor, 401 Sunset Ave., Windsor, ON, Canada, N9B 3P4

Email:az3@uwindsor.ca 


\begin{abstract}
In this paper, data sets for mean velocity distributions in smooth shallow open channel flow are reconsidered to evaluate the characteristics of the overlap region and estimate the friction velocity $\left(\mathrm{u}_{*}\right)$. Both new and existing velocity measurements are used in the analysis. The velocity profiles are obtained using laser Doppler velocimetry and particle image velocimetry at typical Reynolds numbers $(20,000-60,000)$ achieved in laboratory flumes. Validation of the estimated $\mathrm{u}_{*}$ values using different forms of power law is established by comparing these values with the ones available in literature. Also, the Reynolds shear stress distribution based on two-dimensional measurements validate the estimated $u_{*}$. The availability of new data sets allows one to verify the usefulness of the log-law and evaluate the log-law constants. Different fitting methods; least squares, derivative and scattered methods are used to evaluate the value of von Kármán coefficient. It is found that the value of $\kappa$ obtained from the least squares method varies between 0.35 and 0.51 and depends on the Reynolds number. This refutes the conventional constant value assumption for the von Kármán coefficient $(\kappa=0.41)$. By considering the Prandtl's mixing-length theory, the present values of the von Kármán coefficient are used to evaluate the mixing length distributions. The mixing length distributions in smooth open channel flow are found to depend on $\operatorname{Re}_{\theta}$.
\end{abstract}

Keywords: eddy viscosity; friction velocity, power law; log-law; mixing length; smooth open channel flow; velocity measurement; von Kármán coefficient 


\section{Introduction}

The properties of near-bed flows have been investigated because of their importance in many engineering applications. The limited availability of large-scale experimental facilities, the exorbitant costs involved in operating such facilities and the difficulties associated with acquiring reliable measurement data have resulted in the vast majority of laboratory experiments being conducted at relatively lower Reynolds numbers. Furthermore, it is critical to better understand the near-wall flow over the bed at relatively low Reynolds numbers because of its importance in numerical analysis of turbulent flows. Although a significant body of literature has been developed using direct numerical simulation (DNS) to solve the Navier-Stokes equations, its use is still mostly restricted to flows at low Reynolds numbers. Therefore, to develop predictive methods for calculating near-wall turbulence, one must continue to rely on appropriate turbulence models. Model developers must carefully formulate and validate their turbulence models using experimental studies and databases. This provides additional motivation for experimentalists to continue to design high-quality experiments in an effort to refine the near-bed data in turbulent boundary layer flows. Also, as a conceptual study, flow over a smooth bed is still of interest to many researchers in both open channel and turbulent boundary layer flow (Roussinova et al. 2008; Afzal et al. 2009; Gaudio and Dey 2013; Segalini et al. 2013) .

In the near-bed region, the flow strongly depends on the wall shear stress $\left(\tau_{\mathrm{w}}\right)$, density $(\rho)$, kinematic viscosity $(v)$ and vertical distance from the wall $(y)$. As such, the appropriate velocity and length scales are friction velocity $\mathrm{u}_{*}\left(=\sqrt{\tau_{\mathrm{w}} / \rho}\right)$ and the viscosity dependent characteristic length $v / u_{*}$, respectively. The wall bounded flow is typically divided into different regimes as shown in Figure 1 . In the viscous sublayer, $\mathrm{u}_{*}$ can be easily determined if sufficient velocity measurements are available in this region. In the outer region, the effect of viscosity is inconsequential and the scales depend on the free stream velocity $\left(U_{e}\right)$ and a global length scale such as the boundary layer thickness $(\delta)$. The theoretical description of the turbulent boundary layer provides for the existence of an overlap region at sufficiently high 
Reynolds number, This overlap region, where the inner and outer regions meet, can be described by a proper mathematical functional form (logarithmic or power) from which the friction velocity can be estimated. The specific form of the scaling law in the overlap region depends on the assumptions made in the course of the matching process. Barenblatt (1993) discussed the logarithmic law and the power law derivations using similarity and asymptotic considerations of the kinematic quantities. The log-law assumes that the velocity gradient is independent of fluid viscosity at arbitrarily large Reynolds number. In contrast, the power law assumes that the velocity gradient remains dependent on dynamic viscosity, in other words, at arbitrarily large Reynolds number the effect of the viscosity remains not only in the viscous sublayer, but also in the entire boundary layer (Barenblatt and Prostokishin 1993). One of the controversial questions is whether the Reynolds number independent logarithmic law or the Reynolds number dependent power law is the more appropriate velocity scaling law in the overlap region. Experimental and numerical studies are available to support both descriptions.

Another difficulty in using the log-law method to determine $u_{*}$ is identifying where the logarithmic region starts and ends, especially at low Reynolds numbers (Marusic et al. 2013). In contrast, recognition of the start and end points of the power law region is not that critical. One may consider that the power law is more useful in the determination of the friction velocity since the number of unknown parameters is less than that in the log-law.

In many flow situations, the viscous sublayer is thin and the commonly used velocity measuring instruments are not capable of acquiring accurate velocity information. Different forms of power law have been used to describe the velocity distribution and determine the bed shear stress. In the boundary layer with zero pressure gradient, George and Castillo (1997) considered the inner layer and outer layer and developed a power law velocity profile. Barenblatt et al. $(1993,1997)$ proposed the power law scaling for the dimensionless mean streamwise velocity distribution, considering viscous effects, given by

$$
\mathrm{U}^{+}=\mathrm{C}\left(\mathrm{y}^{+}\right)^{\alpha}
$$


where $\mathrm{U}^{+}=\mathrm{U} / \mathrm{u}_{*}$ and $\mathrm{y}^{+}=\mathrm{yu}_{*} / v$. Several researchers have expressed the parameters $\mathrm{C}$ and $\alpha$ in Eq. (1) as functions of Reynolds number, while Balachandar et al. (2002) has proposed constant values (Table 1).

Another method, similar to the Clauser chart method, was proposed by Buschmann and Meinert (1999). This method determines the friction velocity using the data in the overlap region and a form of the power law given by Eq. (1). Since only data in the overlap region are used, velocity measurements in the viscous sublayer are not required. To estimate the friction velocity, they proposed to curve fit the dimensional linear form of Eq. (1) and calculate the slope of the line $\left(\alpha_{1}\right)$ and intercept value $\left(\beta_{1}\right)$ in the equation

$$
\ln \mathrm{U}=\alpha_{1} \ln \mathrm{y}+\beta_{1} .
$$

Using the values obtained for $\alpha_{1}$ and $\beta_{1}, u_{*}$ is calculated as

$$
\mathrm{u}_{*}=\exp \left(\frac{\beta_{1}+\alpha_{1} \ln v-\ln \mathrm{C}_{1}}{\alpha_{1}+1}\right) .
$$

where $C_{l}=\frac{5 \alpha_{1}+\sqrt{3}}{2 \alpha_{1}}$.

The above discussion indicates that many power law functions are presently in use with different coefficients. These coefficients are generally Reynolds number dependent, which is a point of major disagreement between power law and log-law theories (Buschmann and Meinert 1999 and Vinuesa et al. 2014).

Apart from the power law method, the total stress method has been successfully used to determine the bed shear stress for both smooth and rough wall boundary layers. The total stress method is based on the assumption that a region of constant shear stress, equal to the wall shear stress, exists in the inner part of the boundary layer. The total stress is calculated at the plateau of the Reynolds shear stress profile in the overlap region of the boundary layer by summing the viscous and turbulent stress contributions. Since the viscous shear stress is negligible in the outer region, the Reynolds shear stress $\left(-\overline{u^{\prime} v^{\prime}}\right)$ is the only dominant component for the total shear stress, described by the equation

$$
-\overline{\mathrm{u}^{\prime} \mathrm{v}^{\prime}}=\mathrm{u}_{*}^{2}\left(1-\frac{y}{h}\right) .
$$


Since direct shear measurement is not available, the present study is concerned with applying the various power law methods to estimate the bed shear stress and then revisiting the log-law equation by evaluating the von Kármán coefficient ( $\kappa)$ and log-law constant (B) in uniform shallow open channel flow (OCF). For this purpose, new experiments were conducted in a smooth open channel flow using laser Doppler velocimetry (LDV) and particle image velocimetry (PIV), covering a depth Reynolds number over the range $20,000<\mathrm{Re}_{\mathrm{h}}<$ 60,000 normally encountered in laboratory flumes, where $\mathrm{Re}_{\mathrm{h}}=\frac{h \mathrm{U}_{\mathrm{e}}}{v}$ is based on the water depth, h. The validity of the power law method was established not only with other open channel flow data available in the literature (Nezu and Rodi 1986; Kirkgöz 1989) but also with $\mathrm{u}_{*}$ obtained from the Reynolds shear stress distribution method available from the two component velocity measurements. Different procedures for calculating $\kappa$ are explored using the velocity distributions from the new experiments. Finally, by evaluating the eddy viscosity and implementing the Prandtl's mixing length theory, the dependency of the von Kármán coefficient on Reynolds number is discussed.

\section{Experimental setup}

The present experiments were conducted in a rectangular cross-section open channel flume at the Hydraulic Engineering Laboratory in the Centre for Engineering Innovation (CEI) at the University of Windsor. A schematic of the experimental flume is shown in Figure 2. The flume is $0.80 \mathrm{~m}$ deep, $1.22 \mathrm{~m}$ wide (b) and $16 \mathrm{~m}$ long. An upstream settling tank, flow straightener and turbulence stilling arrangements are used to minimize the entrance effects and lower the inlet turbulence levels. A false bottom was designed and installed inside of the flume to allow for control of the slope of the bed. A downstream weir controls the water depth in the flume. The sidewalls in the mid-portion of the flume are made of transparent acrylic plates to facilitate optical access. The measurement section is located $4.5 \mathrm{~m}$ downstream of the flow straightener. The flow is tripped with a wire attached to the bed 
spanning the width of the flume at $2.5 \mathrm{~m}$ upstream of the measuring section, which allows for faster transition to a fully developed turbulent regime.

Velocity measurements were carried out along the centreline of the flume using twodimensional laser Doppler velocimetry (LDV) and particle image velocimetry (PIV) techniques. The LDV system uses a 300mW Ar-Ion laser. The transmitting probe was fit with a $800-\mathrm{mm}$ focal length lens and mounted on an adjustable tilting table. The measuring volume, based on the Gaussian intensity distribution cut off point, was $0.39 \times 0.39 \times 16.4$ $\mathrm{mm}^{3}$. This facilitated measurements to be made fairly close to the bed. The LDV probe was mounted on a two-dimensional computer controlled traverse system driven by stepper motors with a position accuracy of $\pm 0.01 \mathrm{~mm}$ for each direction. The LDV system was operated in the backward scatter mode.

The PIV system consists of dual pulse Nd:YAG lasers of $532 \mathrm{~nm}$ wavelength and 50 $\mathrm{mJ} /$ pulse. The laser sheet was formed through a $500 \mathrm{~mm}$ spherical lens and expanded through a $-15 \mathrm{~mm}$ cylindrical lens. The light sheet was oriented vertically in $(\mathrm{x}-\mathrm{y})$ plane at the centreline of the flume. The laser sheet was illuminated from the top of the flume while the optical axis of the camera was positioned perpendicular to it. The images were recorded using a PowerViewPlus 4 MP CCD camera with a resolution of $2048 \times 2048$ pixels operating in dual capture mode. A $70-300 \mathrm{~mm}$ Nikkor lens was mounted on the camera and adjusted to give the desired field-of-view. Two thousand image pairs were acquired at a frequency of 1.0 Hz. The images were analyzed using the commercial software Insight $4 \mathrm{G}$, with a $44 \times 44$ pixel interrogation area and 50\% overlap using a Fast Fourier Transform (FFT) correlator. The correlation peak was located within subpixel accuracy using a Gaussian curve-fitting method. This process yielded a final interrogation area with size of $22 \times 22$ pixels. For the average field-of-view of $90 \mathrm{~mm} \times 90 \mathrm{~mm}$ and camera resolution of $2048 \times 2048$ pixels the spatial resolution of the present PIV measurements is $0.50 \mathrm{~mm} /$ pixel. After the correlation analysis was complete, velocity outliers were rejected using the Cellular Neural Network method with a variable threshold as proposed by Shinneeb et al. (2004). This technique uses 
information about the local velocity gradient in the flow to make a suitable choice for the local threshold. The rejected vectors (less than 5\%) were primarily located at the edges of the field-of-view. The rejected vectors were replaced using a Gaussian-weighted interpolation scheme.

The flow was seeded with spherical silver coated glass particles (mean diameter of 10 $\mu \mathrm{m})$ to facilitate the velocity measurements. All measurements were made in the central plane of the channel, where it is generally accepted that the effect of any secondary flow is negligible. It should be noted that secondary flows are not expected to play any major role since the channel aspect ratio (b/h) is greater than five (Nezu and Nakagawa 1993). A summary of important test parameters is given in Table 2. Experiments T1-T5 were conducted with the LDV, while T6 and T7 were conducted using PIV. Here, Froude number $\left(\mathrm{F}_{\mathrm{r}}\right)$ is defined based on the average velocity.

Typical estimates of uncertainty in the mean velocity at different vertical locations for each set are reported in Table 3. The uncertainty analysis was based on the methodology outlined by Moffat (1988). The highest uncertainty estimates in the mean velocity occur near the wall $\left(\mathrm{y}^{+}<15\right)$.

\section{Friction velocity results}

In this study, the different power law methods defined in Table 1, proposed by Barenblatt (1993), Zagarola and Smits (1998), Kailasnath (1993) and Balachandar et al. (2002), have been adopted to determine $\mathrm{u}_{*}$. To validate our implementation, these methods were first used to estimate the friction velocity from previous smooth open channel flow experiments of Nezu and Rodi (1986), Kirkgoz (1989) and Steffler et al. (1983, 1985). Our calculated values for friction velocity obtained from the different power laws are reported in Table 4. All power laws used in Table 4 produced estimates of the friction velocity with less than $4 \%$ difference from the previously reported (estimated) values. The power law methods are easy to implement numerically, since just one unknown parameter $\left(\mathrm{u}_{*}\right)$ has to be 
determined. On the other hand, as will be discussed in Section 4, the composite log-law based on either Coles' or Krogstad's wake function requires the determination of three parameters.

The power law methods used above and that due to Buschmann and Meinert (1999) were also applied to the present measurements. Table 5 presents the estimates for the friction velocities for each experimental set described in Table 2 . It can be observed that $\mathrm{u}_{*}$ determined by applying the different power law methods to the measured data are in good agreement with each other. Although this does not ensure the accuracy of the results, it does confirm that the present measurements are consistent with those of earlier studies. In addition, the Reynolds stress distributions for some of the data sets from the two dimensional measurements were used to validate the friction velocity with the Reynolds stress distribution method. The bed shear stress has been evaluated from the slope of the best fit line of the Reynolds stress profile above the bed. Table 6 shows that the friction velocity results from the Reynolds stress distribution method are in good agreement with the values obtained from the power law methods.

\section{Revisiting the log-law method}

von Kármán (1930) described the mean velocity distribution in the outer region of the boundary layer of pipe flow in a logarithmic form (Pope 2000). Other researchers, including Coles (1956), subsequently modified the log-law equation by adding another term known as a wake function, yielding the modified logarithmic equation for the velocity profile as

$$
\mathrm{U}^{+}=\frac{1}{\kappa} \ln \mathrm{y}^{+}+\mathrm{B}+\frac{2 \Pi}{\mathrm{\kappa}} \mathrm{w}(\eta)
$$

The coefficient $\kappa$ is referred to as the von Kármán constant, and is considered to have a universal value of 0.41 . The value of the constant B depends on flow type, geometry and wall conditions. Discussion about the universality of $\kappa$ and B is presented in section 4.1. In Eq. (5), $w(\eta)$ is the wake function and $\eta=y / \delta$, where $\delta$ is the boundary layer thickness defined as the distance from the wall where the velocity is equal to $99 \%$ of the free stream velocity. The parameter $\Pi$ in Eq. (5) determines the strength of the wake. For the zero pressure gradient 
turbulent boundary layer, the value of $\Pi$ has been regarded as a constant. However, Afzal et al. (2009) have shown that $\Pi$ is dependent on the nature of the near-wall perturbations imposed on the boundary layer. In the case of open channel flow, the value of $\Pi$ and the wake function can also be influenced by the presence of the free surface, especially in shallow flow (Balachandar et al. 2002). Different functional forms have been proposed for the wake function in the case of turbulent boundary layer flow over a smooth wall, with the most commonly used forms being those proposed by Coles (1956),

$$
w(\eta)=\sin ^{2}\left(\frac{\pi}{2} \eta\right)
$$

and by Krogstad et al. (1992),

$$
w(\eta)=\frac{1}{2 \Pi}[(1+6 \Pi)-(1+4 \Pi) \eta] \eta^{2} .
$$

Nezu and Rodi (1986) and Kirkgöz (1989) have checked the validity of the Coles wake function as applied to OCF and obtained values of $\Pi=0.20$ and 0.10 , respectively. By applying Coles' equation, Cardoso et al. (1991) noted that $\Pi$ varies between -0.02 and 0.27 in smooth uniform OCF. The wake function (Eq. (7)) proposed by Krogstad et al. (1992) has been validated for flow in open channels by Tachie et al. (2000) and Afzal et al. (2009). The value of $\Pi$ for smooth OCF has been reported to be between 0.10 and 0.16 based on different channel aspect ratios (Roussinova et al. 2008). Furthermore, bed roughness has also been shown to influence the value of the wake parameter П (Krogstad et al. 1992).

\section{1 von Kármán constant or von Kármán coefficient?}

The value of $\kappa$ can be very important in industrial applications. Most turbulence models used in commercial computational fluid dynamics software rely on the assumption that the near-wall flow can be described by Eq. (5). However, Spalart (2006) has suggested that a 2\% decrease in $\kappa$ produces a $1 \%$ decrease in the overall drag estimate. In this case, aircraft manufacturers would prefer to perform simulations using a smaller value of $\kappa$, since the fuel consumption would appear to be more economical than a competitor's estimate with a higher value of $\kappa$ (George 2007). 
For many years, turbulence researchers were content to use $\kappa=0.41$, and thereby implicitly accepted that $\kappa$ was a universal constant. However, different approaches to determine the von Kármán constant from velocity measurements have been proposed and, in the earliest field experiments by Sheppard (1947) and Pasquill (1950), $\kappa$ was found to be 0.46 and 0.37 , respectively. Later, in the well-known Kansas experiments, a smaller value of $\kappa=$ 0.35 was obtained by Businger et al. (1971) for atmospheric boundary layers.

There have also been attempts to mathematically compute $\kappa$ for flow over a smooth wall with homogeneous turbulence. For instance, Long et al. (1993) analyzed the turbulent flow in smooth pipes and obtained $\kappa=0.408$. Lo et al. (2005) estimated $\kappa$ for wall-bounded turbulence based on the similarity with homogeneous constant shear turbulence, and obtained $\kappa=0.42$. Gaudio and Dey (2013) reported that $\kappa$ is not universal in flows with bed and suspended load transport. To date, the research community has not been able to reach a consensus on a single value for $\kappa$, with the values ranging between 0.36 and 0.44 for different canonical flow cases. Table 7 shows values of $\kappa$ from several sources. It has only very recently become more common to refer to $\kappa$ as the von Kármán coefficient (rather than a constant), thereby allowing for a pressure gradient dependence (Nickels 2004; Nagib and Chauhan 2008).

There is even less consensus in the literature about the value of coefficient B in Eq. (5). In a zero pressure gradient turbulent boundary layer, traditional estimates of B range between 4.9 and 5.1. Recent estimates cover a much wider range of B from 4 to 10 . Surprisingly, the lack of apparent universality of B seems to be of far less concern than the precise value of $\kappa$ (George 2007).

The present study is also concerned with evaluating the von Kármán coefficient ( $\kappa)$ and log-law constant (B) in uniform OCF. Different methods for calculating $\kappa$ are discussed here in order to revisit the log-law equation and determine whether or not $\kappa$ can be considered as a universal constant in shallow OCF. 


\subsection{Evaluation of von Kármán coefficient}

If the friction velocity is known, the von Kármán coefficient can be calculated using three methods. They are described below and are denoted as derivative, scatter and fitting methods. The corresponding von Kármán coefficient calculated by these methods is denoted as $\kappa_{\text {der }}, \kappa_{\mathrm{s}}$ and $\kappa_{\mathrm{f}}$, respectively.

\subsubsection{Derivative method}

At relatively high $\mathrm{Re}_{\theta}$, the value of $\kappa$ can be found by using the logarithmic law of the wall. Neglecting the wake function and differentiating Eq. (5) gives

$$
\frac{\mathrm{dU}^{+}}{\mathrm{dy}^{+}}=\frac{1}{\kappa} \frac{1}{\mathrm{y}^{+}}
$$

As a result, $\frac{\mathrm{dU}^{+}}{\mathrm{dy}^{+}}$is a linear function of $\frac{1}{\mathrm{y}^{+}}$, with slope $\frac{1}{\kappa}$. The variation of $\frac{\mathrm{dU}^{+}}{\mathrm{dy}^{+}}$versus $\frac{1}{\mathrm{y}^{+}}$is illustrated in Figure 3 for each of the experiments in this study. The slope of the best-fit line passing through the origin represents the inverse of the von Kármán coefficient. This procedure is sensitive to noise and data scatter due to the inherent uncertainty associated with experimental data. The experimental uncertainties are further amplified when $\frac{\mathrm{dU}^{+}}{\mathrm{dy}^{+}}$is calculated directly by using finite difference on the experimental data. To overcome this difficulty, a common remedy is to average multiple profiles in the log-law region. Since this remedy is not applied here, small fluctuations in $\frac{\mathrm{dU}^{+}}{\mathrm{dy}^{+}}$profiles are observed in Figure 3. Throughout this paper, $\frac{\mathrm{dU}^{+}}{\mathrm{dy}^{+}}$is determined numerically using a second-order central-difference scheme. In the derivative method, the log-law region is considered to occur between $70<\mathrm{y}^{+}<$ 700, where $\mathrm{y}^{+}\left(\frac{\mathrm{dU}^{+}}{\mathrm{dy}^{+}}\right)$should reach a constant value (Österlund et al., 2000).

The analytical expression for calculating the von Kármán coefficient $\left(\kappa_{\mathrm{der}}\right)$ can be written as

$$
\frac{1}{\kappa_{\mathrm{der}}}=\frac{1}{\mathrm{~N}} \sum_{\mathrm{i}=1}^{\mathrm{N}}\left[\mathrm{y}_{\mathrm{i}}{ }^{+}\left(\frac{\mathrm{dU}^{+}}{\mathrm{dy}^{+}}\right)_{\mathrm{i}}\right]
$$


where $\mathrm{N}$ is the number of data points located in the logarithmic region. For all experimental runs (T1-T7), the correlation coefficient of the expected line and the experimental data was above $95 \%$, and the values of $\kappa_{\text {der }}$ are shown in Figure 3 .

\subsubsection{Scatter method}

The scatter method, which has recently been discussed by Segalini et al. (2013), is based on neglecting the wake function and re-arranging Eq. (5) in the form

$$
\kappa \mathrm{B}=\kappa \mathrm{U}^{+}-\ln \mathrm{y}^{+} .
$$

Each pair of $\mathrm{y}_{\mathrm{i}}^{+}, \mathrm{U}_{\mathrm{i}}^{+}$values that belong to the overlap region should follow Eq. (10), with corresponding coefficients denoted as $\kappa_{s}$ and $B_{s}$. In other words, for all pairs of $\left(\mathrm{y}_{i}^{+}, \mathrm{U}_{\mathrm{i}}^{+}\right)$in the overlap region, B can be calculated from Eq. (10) for a specific $\kappa$ value. As $\kappa$ varies, the calculated B will change respectively for all pairs of $\left(\mathrm{y}_{\mathrm{i}}^{+}, \mathrm{U}_{\mathrm{i}}^{+}\right)$in the overlap region. Figure 4 shows that different values of $B$ are obtained in the overlap region when $\kappa \neq \kappa_{s}$. For this method the overlap region is supposed to be between $30<\mathrm{y}_{\mathrm{i}}^{+}<0.2 \delta^{+}$. As discussed in Segalini et al. (2013), having a large number of velocity measurements in this region increases the accuracy of the prediction. Theoretically, in this method, obtaining a proper estimate for the von Kármán coefficient requires the collapse of all pairs of $\left(\mathrm{y}_{\mathrm{i}}^{+}, \mathrm{U}_{\mathrm{i}}^{+}\right)$of the overlap region to one point $\left(\kappa_{\mathrm{s}}, \mathrm{B}_{s}\right)$. In the practical solution, the pairs of $\left(\mathrm{y}_{\mathrm{i}}^{+}, \mathrm{U}_{\mathrm{i}}^{+}\right)$will lie on

a short line, whose centre is located at $\left(\kappa_{\mathrm{s}}, \mathrm{B}_{s}\right)$ and the ends are located at $\left(\kappa_{\mathrm{s}}, \mathrm{B}_{\mathrm{s}} \pm \frac{\Delta B}{2}\right)$. Figure 4 shows the evaluated values for $\kappa_{\mathrm{s}}$ and $\mathrm{B}_{S}$ for the present experiments.

\subsubsection{Fitting method (least-squares method)}

This method is equivalent to the classical approach used for the estimation of the von Kármán coefficient and it is mostly used to determine the shear velocity under the assumption that $\kappa$ and B take universal values. Since, according to Eq. (5), the velocity profile in the logarithmic region should obey the linear relationship between $\mathrm{U}^{+}$and $\ln \mathrm{y}^{+}$, the values of $\kappa$ 
and $\mathrm{B}$ can be determined through a least-squares linear fit (the wake function is neglected). By minimizing the error from the least-squares, the values of $\kappa_{\mathrm{f}}$ and $\mathrm{B}_{\mathrm{f}}$ can be obtained:

$$
\begin{aligned}
\kappa_{\mathrm{f}} & =\frac{\mathrm{N} \sum_{\mathrm{i}=1}^{\mathrm{N}} \ln ^{2} \mathrm{y}_{\mathrm{i}}^{+}-\left(\sum_{\mathrm{i}=1}^{\mathrm{N}} \ln \mathrm{y}_{\mathrm{i}}^{+}\right)^{2}}{\mathrm{~N} \sum_{\mathrm{i}=1}^{\mathrm{N}} \mathrm{U}_{\mathrm{i}}^{+} \ln \mathrm{y}_{\mathrm{i}}^{+}-\sum_{\mathrm{i}=1}^{\mathrm{N}} \mathrm{U}_{\mathrm{i}}^{+} \sum_{\mathrm{i}=1}^{\mathrm{N}} \ln \mathrm{y}_{\mathrm{i}}^{+}} \\
\mathrm{B}_{\mathrm{f}} & =\frac{\sum_{\mathrm{i}=1}^{\mathrm{N}} \ln ^{2} \mathrm{y}_{\mathrm{i}}^{+} \sum_{\mathrm{i}=1}^{\mathrm{N}} \mathrm{U}_{\mathrm{i}}^{+}-\left(\sum_{\mathrm{i}=1}^{\mathrm{N}} \ln \mathrm{y}_{\mathrm{i}}^{+}\right)\left(\sum_{\mathrm{i}=1}^{\mathrm{N}} \ln \mathrm{y}_{\mathrm{i}}^{+} \mathrm{U}_{\mathrm{i}}^{+}\right)}{\mathrm{N} \sum_{\mathrm{i}=1}^{\mathrm{N}} \ln ^{2} \mathrm{y}_{\mathrm{i}}^{+}-\left(\sum_{\mathrm{i}=1}^{\mathrm{N}} \ln \mathrm{y}_{\mathrm{i}}^{+}\right)^{2}}
\end{aligned}
$$

The accuracy obtained from the least-squares fit is sensitive to the number of velocity measurements in the overlap region and the lower and upper bounds of the logarithmic region. In this study, $70<\mathrm{y}_{\mathrm{i}}^{+}<700$ is chosen for the bound of the logarithmic region. The values of $\kappa_{\mathrm{f}}$ and $\mathrm{B}_{\mathrm{f}}$ obtained from the least-squares method are summarized in Table 8 . Here, the regression correlation coefficient is above $99 \%$ for all tests. Table 8 also includes the estimates for $\kappa$ and $\mathrm{B}$ obtained from the derivative and scatter methods.

The above methods lead to different values of $\kappa$ and B for the same flow condition (e.g., test condition T2). The difference is primarily because of the uncertainty in each method and the number of points that correspond to the log-law region. Additional details for uncertainty evaluation can be found in the study by Segalini et al. (2013). In the current study, the results show that the least-squares method predicts the values for $\mathrm{\kappa}$ and $\mathrm{B}$ with higher regression correlation coefficient value compared to the derivative method. Also it should be mentioned that one of the advantages of the least-squares method lies in the simultaneous evaluation of $\kappa$ and $\mathrm{B}$, unlike the derivative method. In addition, in the scatter method, $\mathrm{B}$ is assumed to be dependent on the value of $\kappa$ but not vice versa, whereas these parameters are dependent on each other. Different $\kappa$ values provide different slopes for the streamwise mean velocity profiles in the overlap region compared to the universal value. Applying the least-squares method on other smooth OCF experimental data by Nezu and Rodi (1986), Kirkgoz (1989) and Steffler et al. $(1983,1985)$ shows that the von Kármán coefficient varies between 0.35 and 0.51 and the variation of $B$ is from 3.0 to 7.6 , which is consistent with the results from the current experiments. The least-squares method is used in the remainder of this paper and the proposed values for the log-law coefficients are based on this method. 


\subsection{Velocity profile and log-law}

The streamwise mean velocity profiles in inner scaling for the present tests $\mathrm{T} 1-\mathrm{T} 7$ are shown in Figure 5. As stated above, the friction velocity is evaluated from the power law equations and the values for $\kappa$ and B are obtained from the least-squares method. Moreover, for tests $\mathrm{T} 1, \mathrm{~T} 4$ and $\mathrm{T} 7$, one measurement was available in the viscous sublayer that shows agreement with the viscous sublayer law $\left(\mathrm{U}^{+}=\mathrm{y}^{+}\right)$. This provides an endorsement of the method used for evaluating the shear velocity. On the other hand, for large $\mathrm{y}^{+}$values $\left(\mathrm{y}^{+}>\right.$ 700) the experimental data does not obey the trend of the overlap region. This is due to the wake feature which is more obvious in tests $\mathrm{T} 2, \mathrm{~T} 6$ and $\mathrm{T} 7$.

The variation of von Kármán coefficient observed in this study is in agreement with the findings of other studies by Coleman $(1981,1986)$ and Gaudio and Dey (2013). Different relations have been proposed to define the dependency of $\kappa$ on Reynolds number. The most well known equations are Simpson's (1970) interpretation and Wosnik et al. (2000) estimation. In the current work, the classical Prandtl's mixing-length theory is applied to evaluate the von Kármán coefficient. Determination of mixing length for different velocity profiles requires the eddy viscosity evaluation and its variation along the depth of flow.

\subsection{Eddy viscosity}

As discussed earlier, the most common wake functions used for the outer region are those proposed by Krogstad (Eq. (7)) and Coles (Eq. (6)). By applying these wake functions and finding the wake parameter for each velocity profile, the eddy viscosity can be obtained. Based on Reynolds number, the eddy viscosity and mixing length can change and as a result the von Kármán coefficient can be affected.

In fully developed two-dimensional open channel flow, the total shear stress can be evaluated as (Cebeci and Smith 1974): 


$$
-\overline{u^{\prime} v^{\prime}}+v \frac{d U}{d y}=u_{*}^{2}(1-\eta)
$$

Here $-\overline{u^{\prime} v^{\prime}}$ is the Reynolds shear stress and $\eta=y / \delta$. One of the simplest models to eliminate the Reynolds shear stress in Eq. (12) is to use the concept of eddy viscosity, defined by $-\overline{u^{\prime} v^{\prime}}=v_{t} \frac{d U}{d y}$. Combining this with Eq. (12) yields the following expression for the eddy viscosity:

$$
v_{\mathrm{t}}=\mathrm{u}_{*}^{2}(1-\eta)\left(\frac{\mathrm{dU}}{\mathrm{dy}}\right)^{-1}
$$

Eq. (13) can be used to evaluate eddy viscosity if explicit information for the velocity distribution is available. Using Coles' wake function for high Reynolds numbers, the eddy viscosity is given by

$$
\frac{v_{t}}{u_{*} \delta}=\kappa(1-\eta)\left(\frac{1}{\eta}+\pi \Pi \sin \eta \pi\right)^{-1}
$$

Although the effect of the wake parameter $\Pi$ on eddy viscosity is often neglected, Nezu and Rodi (1986) were among the first to show a significant effect of $\Pi$ on eddy viscosity, especially in the overlap and outer regions.

Another expression for the eddy viscosity can be obtained by applying the wake function proposed by Krogstad et al. (1992), yielding

$$
\frac{v_{t}}{u_{*} \delta}=\kappa(1-\eta)\left[\frac{1}{\eta}+2(1+6 \Pi) \eta-3(1+4 \Pi) \eta^{2}\right]^{-1} .
$$

Figures $6 \mathrm{a}$ and $6 \mathrm{~b}$ show profiles of eddy viscosity for all experimental cases (T1-T7; Nezu and Rodi 1986; Kirkgoz 1989; Roussinova et al. 2008; Afzal et al. 2009) together with the curves according to Eqs. (14) and (15). As observed in Figure 6a, the eddy viscosity based on Coles' wake function (Eq. (14)) starts from zero near the bed, attains a maximum at $\mathrm{y} / \delta \approx 0.5$ and terminates at zero for $\mathrm{y}=\delta$. This is different from Spalart's (1988) DNS prediction at $\mathrm{y}=$ $\delta$. Krogstad's wake function, on the other hand, shown in Figure $6 \mathrm{~b}$ produces results similar to Spalart's (1988) for the eddy viscosity. Also, the maximum dimensionless eddy viscosity value evaluated using Eq. (15) is 0.091, which is close to the value reported by Spalart (1988). Thus, we have established the existence of a sizable logarithmic region in all experimental data and that the eddy viscosity distribution can be evaluated using a composite 
velocity profile incorporating the wake function proposed by Krogstad et al. (1992). Given the availability of the OCF velocity profiles, the mixing length is further examined.

\subsection{Mixing length}

The mixing length $\ell_{m}$ is defined as a turbulent length scale that the fluid parcel will travel, conserving its properties, before completely mixing with the surrounding fluid. Based on Prandtl's mixing-length theory, the eddy viscosity is evaluated from the velocity gradient $\mathrm{dU} / \mathrm{dy}$ and the mixing length as

$$
v_{\mathrm{t}}=\ell_{\mathrm{m}}^{2} \frac{\mathrm{dU}}{\mathrm{dy}}
$$

In Eq. (16), the mixing length depends on the nature of the flow and in general, is space dependent (Nezu and Nakagawa 1993). The distribution of $\ell_{m}$ in boundary layer flows has been conventionally described by two separate regions. The first region is the outer region where $\delta$ is assumed as the length scale and the outer mixing length $\left(\ell_{m}\right)_{0}$ is assumed to be proportional to $\delta\left(\ell_{m} \sim \delta\right)_{0}$. In the inner layer, the variation of the mixing length is assumed to be proportional to the distance from the wall $\left(\ell_{m} \sim \mathrm{y}\right)_{\mathrm{i}}$. Based on von Kármán's postulation, the proportionality coefficient is $\kappa$ and the mixing length in the inner region can be determined from the location to the wall $\left(\ell_{m}=\kappa \mathrm{y}\right)_{\mathrm{i}}$. From the latter assumption, the loglaw of the wall was proposed (Cebeci and Smith 1974). Figure 7 shows the variation of normalized mixing length with increase of $y / \delta$, where the mixing length is calculated based on the eddy viscosity obtained from Eq. (15).

As expected, the mixing length changes for different locations, confirming its space dependency. Figure 7 shows that the mixing lengths approach similar values near the wall for all experiments, when the wall distance is normalized in outer scaling. Near the bed at $y / \delta<$ 0.2, all mixing length profiles collapse on to each other, since the effect of the wake parameter in this region is insignificant. Far from the bed $(y / \delta>0.2)$, the mixing length profiles vary at different wall distances because of changes in Reynolds number and wake 
parameter. Also, the effect of the von Kármán coefficient on the mixing length cannot be distinguished well in Figure 7 since the mixing length distribution is plotted in outer scaling.

Figure 8 shows the near-wall variation of normalized mixing length with $\mathrm{y}^{+}$for the range of data near the wall. The linear relation between $\ell_{m} / \delta$ and $\mathrm{y}^{+}$confirms the first assumption for the log-law equation. Here, the linear relation between $\ell_{m} / \delta$ and $\mathrm{y}^{+}$specifies a slope $\kappa_{1}$ (i.e. $\ell_{m} / \delta=\kappa_{1} \mathrm{y}^{+}$) that is not constant but varies according to $\operatorname{Re}_{\theta}$. Figure 8 shows that as $\operatorname{Re}_{\theta}$ increases the coefficient $\kappa_{1}$ decreases, which will ultimately change the von Kármán coefficient. In other words, Figure 8 shows that the von Kármán coefficient is Reynolds number dependent, contradictory to the classical assumption that all the constants in the loglaw equation (Eq. (5)) are independent of Reynolds number.

\subsection{Variation of von Kármán coefficient}

Based on the present LDV measurements and the results discussed above, the classical claim that the von Kármán coefficient has a universal constant value can be refuted, at least in open channel flows. Although many studies show that $\kappa$ varies with Reynolds number (e.g., Zanoun et al. 2003; Segalini et al. 2013), there is still considerable discussion about the relationship between the von Kármán coefficient and Reynolds number.

As discussed above, Figure 8 shows the variation of dimensionless mixing length with $\mathrm{y}^{+}$. This figure elucidates the contribution of the von Kármán coefficient in the variation of mixing length for different test cases. This contribution is identified as parameter $\kappa_{1}$, and its variation with $\operatorname{Re}_{\theta}$ is presented in Figure 9. The Reynolds number $\left(\operatorname{Re}_{\theta}\right)$ range in this study is between 330 and 6200 . Figure 9 shows that $\kappa_{1}$ decreases sharply as $\operatorname{Re}_{\theta}$ increases. For high $\mathrm{Re}_{\theta}, \kappa_{1}$ reaches an asymptotic value of approximately $1.6 \times 10^{-4}$. It should be mentioned that based on the definition for mixing length in the inner region, the von Kármán coefficient is related to $\kappa_{1}$ by

$$
\kappa=\kappa_{1} \delta^{+}
$$


In Eq. (17), $\delta^{+}$is known as the dimensionless boundary layer thickness, which explicitly reveals that there is a separation between the largest and smallest length scales in the flow. $\delta^{+}$is directly proportional to $\operatorname{Re}_{\theta}$ and its variation is shown in the inset of Figure 9. By considering Eq. (17) and Figure 9, the variation of von Kármán coefficient with $\operatorname{Re}_{\theta}$ can be simplified and expressed as

$$
\kappa \approx 0.2725 \operatorname{Re}_{\theta}^{0.031}+42.78 \operatorname{Re}_{\theta}^{-0.969} .
$$

It should be mentioned that Eq. (18), which is derived for near-uniform smooth OCF in a specific range of Reynolds number $\left(\operatorname{Re}_{\theta}=300\right.$ to 6,200$)$, is another way to predict the Kármán coefficient rather than using a constant assumption.

\section{Conclusions}

The evaluation of the bed shear velocity and log-law coefficients in smooth open channel flow are re-examined in this study for $\mathrm{Re}_{\mathrm{h}}<60,000$. The main findings of the present study can be summarized as follows:

- The friction velocity has been evaluated accurately from the streamwise velocity profile at different Reynolds numbers by applying various forms of power law in open channel flow. The power law methods are straightforward to implement numerically as it involves only one unknown.

- The present study discusses various methods used to determine the von Kármán coefficient. Analytical expressions have been developed by different methods for fitting the streamwise velocity profiles. Values of $\kappa$ and B were estimated based on the leastsquares method, since this method has a higher regression correlation and also is more accurate compared to the derivative and scatter methods.

- The mixing length in open channel flow is evaluated based on the eddy viscosity distribution assuming a composite velocity profile incorporating the wake function proposed by Krogstad et al. (1992). The mixing length is found to vary with wall distance, as reported earlier by Nezu and Rodi (1986). This also confirms that the size of 
eddies is proportional to their distance from the wall. In the outer region, far from the bed $(y / \delta>0.2)$, the flow Reynolds number and wake strength influence the mixing length. In contrast, in the inner region, the mixing length is only a function of the distance from the wall and $\mathrm{Re}_{\theta}$. The Reynolds number effect on the inner mixing length is presented as the coefficient $\kappa_{1}$ and $\delta^{+}$which, when multiplied together gives the von Kármán coefficient $\kappa$. In other words, the von Kármán coefficient is not constant and is dependent on Reynolds number. 


\section{References}

Afzal, B., Faruque, M.A.A., Balachandar, R. 2009. Effect of Reynolds number, near-wall perturbation and turbulence on smooth open channel flows. Journal of Hydraulic Research, $47(1), 66-81$.

Balachandar, R., Blakely, D., Bugg, J. 2002. Friction velocity and power law velocity profile in smooth and rough shallow open channel flows. Canadian Journal of Civil Engineering, 29, 256-266.

Barenblatt, I. 1993. Scaling laws for fully developed turbulent shear flows. Part 1. Basic hypothesis and analysis. Journal of Fluid Mechanics, 248, 513-520.

Barenblatt, I., Chorin, J., Prostokishin, V.M. 1997. Scaling laws for fully developed turbulent flow in pipes. Applied Mechanics Reviews, 50(7), 413-429.

Barenblatt, I., Prostokishin, V.M. 1993. Scaling laws for fully developed turbulent shear flows. Part 2. Processing of experimental data. Journal of Fluid Mechanics, 248, 521-529.

Buschmann, M.H., Meinert, J. 1999. Power law or log law for turbulent boundary layers with low Reynolds number? Colloquium Fluid Dynamics'99, Prague, Czech Rep.

Businger, J.A., Wyngaard, J.C., Izumi, I., Bradley, E.F. 1971. Flux-profile relationships in the atmospheric surface layer. Journal of Atmospheric Sciences, 28, 181-189.

Cardoso, A.H., Gust, G., Graf, W.H. 1991. Steady gradually accelerating flow in a smooth open channel. Journal of Hydraulic Research, 29(4), 525-543.

Cebeci, T., Smith, A.M.O. 1974. Analysis of Turbulent Boundary Layers. Academic Press, New York.

Coleman, N.L. 1981. Velocity profile with suspended sediment. Journal of Hydraulic Research, 19(3), 211-229.

Coleman, N.L. 1986. Effects of suspended sediment on the open-channel velocity distribution. Water Resource Research, 22(10), 1377-1384.

Coles, D.E. 1956. The law of the wake in the turbulent boundary layer. Journal of Fluid Mechanics, 1, 191-226. 
Francey, R.J., Garratt, J.R. 1981. Interpretation of flux-profile observations at ITCE (1976). Journal of Applied Meteorology and Climatology, 20, 603-618.

Gaudio, R., Dey, S. 2013. Evidence of non-universality of von Kármán’s к. In Experimental and Computational Solutions of Hydraulic Problems. P. Rowinski, ed. Springer, Berlin, Heidelberg, Germany, 71-83.

George, W.K., Castillo, L. 1997. Zero-pressure-gradient turbulent boundary layer. Applied Mechanics Reviews, 50(12), 689-729.

George, W.K. 2007. Is there a universal log law for turbulent wall-bounded flows? Philosophical Transactions of the Royal Society A. 365, 789-806.

Hoyas, S., Jimenez, J. 2006. Scaling of the velocity fluctuations in turbulent channels up to $\operatorname{Re}_{\tau}=2003$. Physics of Fluids, 18, 011702.

Kailasnath, P. 1993. Reynolds Number Effect and the Momentum Flux in Turbulent Boundary Layer. PhD Thesis, Department of Mechanical Engineering, Yale Univ., New Haven, CT, USA.

Kim, J., Moin, P., Moser, R. 1987. Turbulent statistics in fully developed channel flow at low Reynolds number. Journal of Fluid Mechanics, 177, 133-160.

Kirkgoz, M.S. 1989. Turbulent velocity profiles for smooth and rough open channel flow. Journal of Hydraulic Engineering, 115, 1543-1561.

Krogstad, P., Antonia, R., Browne, L.W.B. 1992. Comparison between rough and smoothwall turbulent boundary layers. Journal of Fluid Mechanics, 245, 599-617.

Lo, T.S., L'vov, V.S., Pomyalov, A., Procaccia, I. 2005. Estimating von Kármán's constant from homogeneous turbulence. Europhysics Letters, 72(6), 943-949.

Long, C.E., Wiberg, P.L., Nowell, A.R.M. 1993. Evaluation of von Kármán's constant from integral flow parameters. Journal of Hydraulic Engineering, 119, 1182-1190.

Marusic, I., Monty, J.P., Hultmark, M., Smits, A. J. 2013. On the logarithmic region in wall turbulence. Journal of Fluid Mechanics, 716, R3-1 - R3-11

Moffat, R.J. 1988. Describing the uncertainties in experimental results. Experimental Thermal and Fluid Science, 1, 3-17. 
Moser R.D., Kim, J., Mansour N.N. 1999. Direct numerical simulation of turbulent channel flow up to $\operatorname{Re}_{\tau}=590$. Physics of Fluids, 11, 943-945.

Monty, J.P. 2005. Developments in Smooth Wall Turbulent Duct Flows. PhD Thesis, The University of Melbourne, Melbourne, Australia.

Nagib, H.M., Chauhan, K.A. 2008. Variations of von Kármán coefficient in canonical flows. Physics of Fluids, 20 (101518), 1-10.

Nezu, I., Nakagawa, H. 1993. Turbulence in open channel flows. International Association for Hydraulic Research, A.A. Balkema Publishers, Rotterdam.

Nezu, I., Rodi, W. 1986. Open channel flow measurements with a laser Doppler anemometer. Journal of Hydraulic Engineering, 112(5), 335-355.

Nickels, T.B. 2004. Inner scaling for wall-bounded flows subject to large pressure gradients. Journal of Fluid Mechanics, 521, 217-239.

Oncley, S.P, Itsweire, E.C., Friehe, C.A., LaRue, J.C., Chang, S.S. 1990. Surface layer profiles and turbulence measurements over uniform land under near-neutral conditions. 9th Symposium on Turbulence and Diffusion, Roskilde, Denmark, 237-240.

Österlund, J.M., Johansson, A.V., Nagib, H.M., Hites, M.H. 2000. A note on the overlap region in turbulent boundary layers. Physics of Fluids, 12 (1), 1-4.

Pasquill, F. 1950. The aerodynamic drag of grassland, Proceedings of the Royal Society of London A: Mathematical, Physical and Engineering Sciences, A202, 143-153.

Pope, S.B. 2000. Turbulent Flows. Cambridge University Press, New Delhi, India.

Roussinova,V., Biswas, N., Balachandar, R. 2008. Revisiting turbulence in smooth uniform open channel flow. Journal of Hydraulic Research, 46(Extra Issue 1), 36-48.

Segalini, A., Orlu R., Alfredsson, P.H. 2013. Uncertainty analysis of the von Karman constant. Journal of Experimental Fluids, 54:1460, 1-9.

Sheppard, P.A. 1947. The aerodynamic drag of the Earth's surface and the value of Karman's constant in the lower atmosphere. Proceedings of the Royal Society of London A: Mathematical, Physical and Engineering Sciences, A188, 208-222. 
Shinneeb, A.M., Bugg, J.D., Balachandar, R. 2004. Variable threshold outlier identification in PIV data. Measurement Science and Technology, 15(9), 1722.

Simpson, R.L. 1970. Characteristics of turbulent boundary layers at low Reynolds numbers. Journal of Fluid Mechanics, 42, 769-802.

Spalart, P.R. 1988. Direct simulation of a turbulent boundary layer up to $\operatorname{Re}=1410$. Journal of Fluid Mechanics, 187, 61-98.

Spalart, P.R. 2006. Turbulence: Are we getting smarter? Fluid Dynamics Award Lecture, 36th Fluid Dynamics Conference and Exhibit, San Francisco, CA, USA.

Steffler, P.M., Rajaratnam, N., Peterson, A.W. 1985. LDA measurements in open channel. Journal of Hydraulic Engineering, 111(1), 119-130.

Steffler, P.M., Rajaratnam, N., Peterson, A.W. 1983. LDA measurements of mean velocity and turbulence distribution in a smooth rectangular open channel. Water Resource Engineering Report 83-4, Department of Civil Engineering, The University of Alberta, Edmonton, Alberta, Canada.

Tachie, M.F., Bergstrom, D.J., Balachandar, R. 2000. Rough wall turbulent boundary layers in shallow open channel flow. Journal of Fluids Engineering, 122, 533-541.

Tennekes, H. 1973. The logarithmic wind profile. Journal of the Atmospheric Sciences, 30, $234-238$.

Vinuesa, R., Schlatter, P., Nagib, H.M. 2014. Role of data uncertainties in identifying the logarithmic region of turbulent boundary layers. Experiments in Fluids, 55(6), 1-13.

von Kármán, T. 1930. Mechanische änlichkeit und turbulenz. Nachrichten von der Gesellschaft der Wissenschaften zu Göttingen, Mathematisch-Physikalische Klasse, 1930, $58-76$.

Wosnik, M., Castillo, L. George, W.K. 2000. A theory for turbulent pipe and channel flows. Journal of Fluid Mechanics, 421, 115-145.

Zagarola, M.V., Smits, A.J. 1997. Scaling of the mean velocity profile for turbulent pipe flow. Physical Review Letters, 78(2), 239-242. 
Zagarola, M.V., Smits, A.J. 1998. A new mean velocity scaling for turbulent boundary layers. Proc. ASME FEDSM'98. 4950, Washington DC, USA, 1-6.

Zanoun, E.-S., Durst, F., Nagib, H. 2003. Evaluating the law of the wall in two-dimensional fully developed turbulent channel flows. Physics of Fluids, 15, 3079-3089. 


\section{List of symbols}

$\mathrm{B}=\log$-law of the wall constant (-)

$\mathrm{B}_{\mathrm{f}}=\log$-law of the wall constant by fitting method (-)

$\mathrm{B}_{\mathrm{s}}=\log$-law of the wall constant by scatter method (-)

$\mathrm{C}=$ coefficient (-)

$\mathrm{C}_{\mathrm{l}}=$ coefficient (-)

$\mathrm{F}_{\mathrm{r}}=$ Froude number based on the average velocity (-)

$\mathrm{h}=$ water depth $(\mathrm{m})$

$\operatorname{Re}_{\mathrm{D}}=$ Reynolds number based on pipe diameter (D) and friction velocity (-)

$\mathrm{Re}_{\mathrm{h}}=$ Reynolds numbers based on the water depth (h) and free stream velocity (-)

$\operatorname{Re}_{\mathrm{R}}=$ Reynolds number based on hydraulic radius $\left(\mathrm{R}_{\mathrm{h}}\right)$ and mean velocity (-)

$\operatorname{Re}_{\theta}=$ Reynolds number based on momentum thickness $(\theta)$ and free stream velocity (-)

$\mathrm{U}=$ mean streamwise velocity $\left(\mathrm{ms}^{-1}\right)$

$\mathrm{U}_{\mathrm{m}}=$ depth-averaged streamwise velocity $\left(\mathrm{ms}^{-1}\right)$

$\mathrm{U}^{+}=$dimensionless mean streamwise velocity, normalized by friction velocity (-)

$\mathrm{u}_{*}=$ friction velocity $\left(\mathrm{m} \mathrm{s}^{-1}\right)$

$\mathrm{U}_{\mathrm{e}}=$ free stream velocity $\left(\mathrm{m} \mathrm{s}^{-1}\right)$

$-\overline{\mathrm{u}^{\prime} \mathrm{v}^{\prime}}=$ Reynolds shear stress $\left(\mathrm{m}^{2} \mathrm{~s}^{-2}\right)$

$\mathrm{y}=$ normal distance from the wall $(\mathrm{m})$

$\mathrm{y}^{+}=$normalized distance from the wall, scaled by viscous length (-)

$\alpha=$ coefficient (-)

$\alpha_{1}=\operatorname{coefficient}(-)$

$\beta_{1}=$ coefficient $(-)$

$\delta=$ boundary layer thickness $(\mathrm{m})$

$\delta^{+}=$dimensionless boundary layer thickness based on the viscous length scale (-)

$\eta=$ normalized distance from the wall, scaled by boundary layer thickness (-)

$\theta=$ momentum thickness $(\mathrm{m})$ 


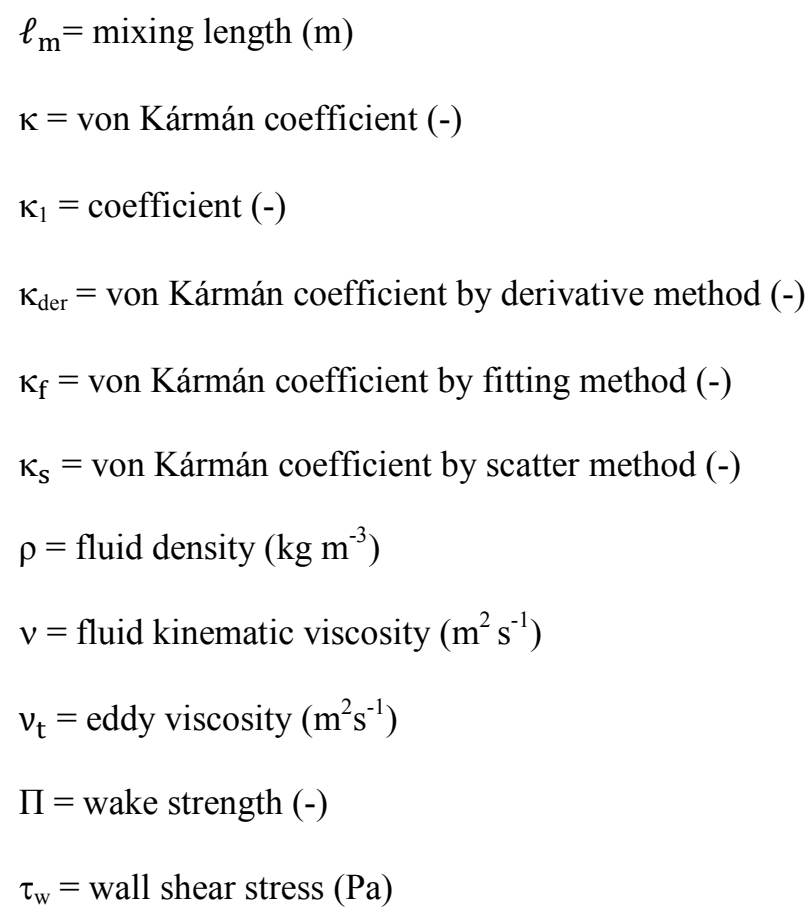


Table 1 Power law $\left(\mathrm{U}^{+}=\mathrm{C}\left(\mathrm{y}^{+}\right)^{\alpha}\right)$ coefficients defined by researchers

\begin{tabular}{|c|c|c|c|}
\hline & Researcher & $\mathrm{C}$ & $\alpha$ \\
\hline \multirow{4}{*}{ 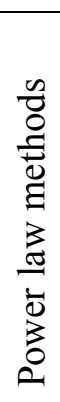 } & Barenblatt (1993) & $\frac{1}{\sqrt{3}} \ln { }^{*} \operatorname{Re}_{\delta}+2.5$ & $\frac{3}{2 \ln \operatorname{Re}_{\delta}}$ \\
\hline & Kailasnath (1993) & $2.8 \mathrm{Re}_{\delta}{ }^{-0.077}+2.277$ & $0.314 \mathrm{Re}_{\delta}^{-0.077}$ \\
\hline & Zagarola et al. (1997) & $0.7053 \ln \mathrm{Re}_{\delta}+0.3055$ & $\frac{1.085}{\ln \operatorname{Re}_{\delta}}+\frac{6.535}{\left(\ln \operatorname{Re}_{\delta}\right)^{2}}$ \\
\hline & Balachandar et al. (2002) & 7.957 & 0.1551 \\
\hline
\end{tabular}

*Reynolds number based on boundary layer thickness $(\delta)$ and depth-averaged velocity $\left(\mathrm{U}_{\mathrm{m}}\right)$ $\left(\operatorname{Re}_{\delta}=\frac{2 \delta U_{m}}{v}\right)$

Table 2 Experimental details

\begin{tabular}{|c|c|c|c|c|c|c|c|}
\hline Test & $\begin{array}{r}\mathrm{U}_{\mathrm{e}} \times 10^{-2} \\
\left(\mathrm{~ms}^{-1}\right)\end{array}$ & $\begin{array}{r}\mathrm{h} \times 10^{-2} \\
(\mathrm{~m})\end{array}$ & $\mathrm{b} / \mathrm{h}$ & $\begin{array}{c}\delta \times 10^{-2} \\
\text { (m) }\end{array}$ & $\operatorname{Re}_{\theta}$ & $\mathrm{F}_{\mathrm{r}}$ & $\mathrm{Re}_{\mathrm{h}}$ \\
\hline T1 & 32.0 & 6.3 & 19.4 & 5.3 & 1,674 & 0.35 & 20,466 \\
\hline $\mathrm{T} 2$ & 24.0 & 15.4 & 7.9 & 8.2 & 1,962 & 0.18 & 36,849 \\
\hline $\mathrm{T} 3$ & 44.8 & 8.4 & 14.5 & 6.8 & 2,987 & 0.44 & 36,418 \\
\hline $\mathrm{T} 4$ & 57.9 & 7.2 & 16.9 & 6.3 & 3,790 & 0.61 & 37,306 \\
\hline T5 & 57.1 & 10.4 & 11.7 & 8.1 & 4,417 & 0.51 & 60,370 \\
\hline T6 & 15.6 & 7.1 & 17.0 & 5.4 & 839 & 0.17 & 10,563 \\
\hline $\mathrm{T} 7$ & 51.1 & 7.1 & 17.0 & 5.1 & 2516 & 0.54 & 33,755 \\
\hline
\end{tabular}


Table 3 Uncertainty estimates for the mean velocity (U)

\begin{tabular}{lccc}
\hline \multirow{2}{*}{ Test } & \multicolumn{3}{c}{ Uncertainty $(\%)$} \\
\cline { 2 - 4 } & Near bed $\left(\mathrm{y}^{+}<15\right)$ & Overlap region & Outer region \\
\hline T1 & 0.8 & 0.5 & 0.4 \\
T2 & 0.7 & 0.5 & 0.4 \\
T3 & 0.6 & 0.5 & 0.4 \\
T4 & 0.7 & 0.5 & 0.4 \\
T5 & 0.5 & 0.5 & 0.4 \\
T6 & 0.7 & 0.4 & 0.4 \\
T7 & 0.5 & 0.4 & 0.4 \\
\hline
\end{tabular}


Table 4 Bed shear velocity, $\mathrm{u}_{*} \times 10^{-2}\left(\mathrm{~ms}^{-1}\right)$ calculated using different power law methods

\begin{tabular}{|c|c|c|c|c|c|c|c|}
\hline \multirow[b]{2}{*}{ Experiments } & \multicolumn{4}{|c|}{ Power law methods } & \multirow{2}{*}{$\begin{array}{c}\text { Average } \\
\text { value }\end{array}$} & \multirow{2}{*}{$\begin{array}{c}\text { Reported } \\
\text { value }\end{array}$} & \multirow{2}{*}{$\begin{array}{c}\text { Difference } \\
(\%)\end{array}$} \\
\hline & $\begin{array}{c}\text { Barenblatt } \\
\text { (1993) }\end{array}$ & $\begin{array}{c}\text { Kailasnath } \\
\text { (1993) }\end{array}$ & $\begin{array}{l}\text { Zagarola and } \\
\text { Smits (1997) }\end{array}$ & $\begin{array}{l}\text { Balachandar } \\
\text { et al. (2002) }\end{array}$ & & & \\
\hline Nezu and Rodi (P1) & 0.42 & 0.43 & 0.41 & 0.43 & 0.42 & 0.43 & 2.3 \\
\hline Nezu and Rodi (P2) ${ }^{*}$ & 0.95 & 0.97 & 0.95 & 0.96 & 0.96 & 0.95 & 1.1 \\
\hline Nezu and Rodi (P3) ${ }^{*}$ & 2.18 & 2.20 & 2.21 & 2.22 & 2.20 & 2.20 & 0.0 \\
\hline Nezu and Rodi (P4) ${ }^{*}$ & 2.98 & 3.01 & 3.03 & 3.04 & 3.02 & 3.04 & 0.7 \\
\hline Nezu and Rodi (P5) ${ }^{*}$ & 4.75 & 4.80 & 4.85 & 4.89 & 4.80 & 4.66 & 3.0 \\
\hline Nezu and Rodi (P6) ${ }^{*}$ & 2.67 & 2.73 & 2.70 & 2.74 & 2.71 & 2.71 & 0.0 \\
\hline Nezu and Rodi (P7) ${ }^{*}$ & 4.05 & 4.09 & 4.11 & 4.12 & 4.09 & 3.99 & 2.5 \\
\hline Nezu and Rodi (P8) ${ }^{*}$ & 2.20 & 2.23 & 2.23 & 2.23 & 2.22 & 2.22 & 0.0 \\
\hline Steffler et al. (SRP1) & 3.34 & 3.38 & 3.38 & 3.36 & 3.37 & 3.35 & 0.6 \\
\hline Steffler et al. (SRP2) & 1.66 & 1.69 & 1.66 & 1.68 & 1.67 & 1.64 & 1.8 \\
\hline $\operatorname{Kirkgoz}(\mathrm{S} 2)^{*}$ & 0.27 & 0.28 & 0.26 & 0.28 & 0.27 & 0.28 & 3.6 \\
\hline Kirkgoz (S3) ${ }^{*}$ & 1.07 & 1.09 & 1.05 & 1.07 & 1.07 & 1.04 & 2.9 \\
\hline Kirkgoz (S4) ${ }^{*}$ & 0.60 & 0.61 & 0.59 & 0.61 & 0.60 & 0.59 & 1.7 \\
\hline Kirkgoz (S5) ${ }^{*}$ & 6.50 & 6.60 & 6.40 & 6.59 & 6.52 & 6.58 & 0.9 \\
\hline Kirkgoz (S6) ${ }^{*}$ & 0.84 & 0.85 & 0.83 & 0.85 & 0.84 & 0.85 & 1.2 \\
\hline Kirkgoz (S10) ${ }^{*}$ & 2.53 & 2.56 & 2.53 & 2.54 & 2.54 & 2.47 & 2.8 \\
\hline Kirkgoz (S12) ${ }^{*}$ & 3.82 & 3.87 & 3.82 & 3.83 & 3.84 & 3.82 & 0.5 \\
\hline
\end{tabular}


Table 5 Estimates for $\mathrm{u}_{*} \times 10^{-2}\left(\mathrm{~ms}^{-1}\right)$ for the present experiments using different power law methods

\begin{tabular}{lcccccc}
\hline & \multicolumn{5}{c}{ Power law methods } & \\
\cline { 2 - 6 } Test & Barenblatt & Kailasnath & Zagarola and & Balachandar & Buschmann and & Average value \\
& $(1993)$ & $(1993)$ & Smits (1997) & et al. (2002) & Meinert (1999) & \\
\hline T1 & 1.43 & 1.45 & 1.43 & 1.44 & 1.42 & $1.43 \pm 0.4 \%$ \\
T2 & 1.06 & 1.07 & 1.07 & 1.07 & 1.06 & $1.07 \pm 0.4 \%$ \\
T3 & 1.89 & 1.91 & 1.91 & 1.91 & 1.88 & $1.90 \pm 0.4 \%$ \\
T4 & 2.37 & 2.40 & 2.39 & 2.39 & 2.36 & $2.38 \pm 0.4 \%$ \\
T5 & 2.31 & 2.34 & 2.33 & 2.33 & 2.31 & $2.33 \pm 0.4 \%$ \\
T6 & 0.75 & 0.77 & 0.74 & 0.77 & 0.76 & $0.76 \pm 0.1 \%$ \\
T7 & 2.18 & 2.20 & 2.17 & 2.18 & 2.16 & $2.18 \pm 0.4 \%$ \\
\hline
\end{tabular}

Table 6 Bed shear velocity comparison using the Reynolds stress and the power law methods

\begin{tabular}{lcc}
\hline \multirow{2}{*}{ Test } & \multicolumn{2}{c}{$\mathrm{u}_{*} \times 10^{-2}\left(\mathrm{~ms}^{-1}\right)$} \\
\cline { 2 - 3 } & Using total stress & $\begin{array}{c}\text { Average value using the } \\
\text { method }\end{array}$ \\
\hline T4 & 2.33 & 2.38 \\
T6 & 0.77 & 0.76 \\
T7 & 2.23 & 2.18 \\
Roussinova et al. 2008 (1) & 2.17 & 2.19 \\
Roussinova et al. 2008 (2) & 2.14 & 2.11 \\
Afzal et al. 2009 (B-SM2) & 1.57 & 1.58 \\
\hline
\end{tabular}


Table 7 Reported values of $\kappa$ from different sources

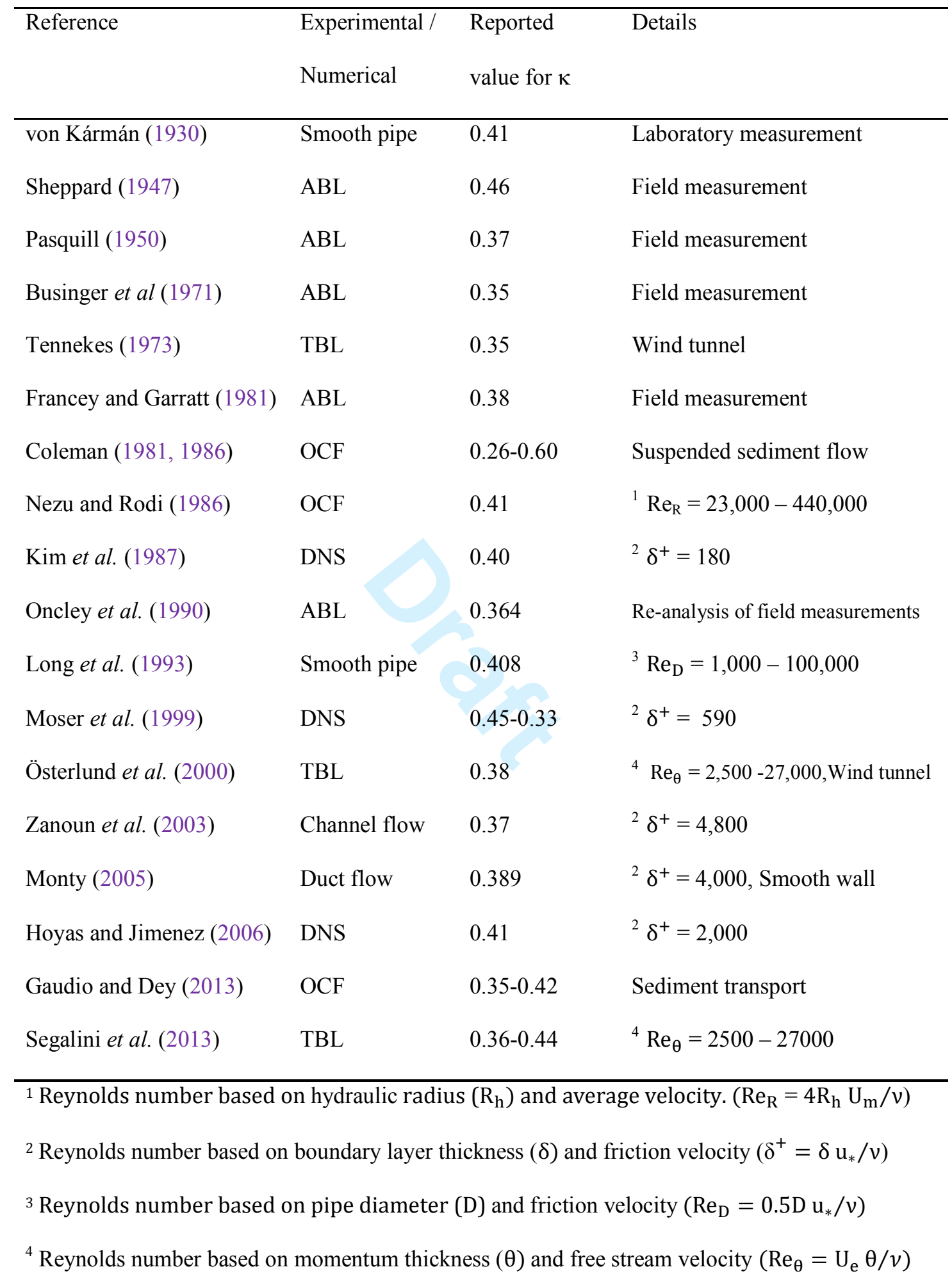


Table 8 Comparison between different methods for $\kappa$ and $\mathrm{B}$

\begin{tabular}{|c|c|c|c|c|c|c|c|c|}
\hline \multirow[b]{2}{*}{ Test } & \multicolumn{2}{|c|}{ Derivative method } & \multicolumn{3}{|c|}{ Scatter method } & \multicolumn{3}{|c|}{ Least-squares method } \\
\hline & $\kappa_{\text {der }}$ & $\mathrm{R}^{2}(\%)$ & $\kappa_{\mathrm{s}}$ & $\mathrm{B}_{\mathrm{s}}$ & $\Delta \mathrm{B} / 2$ & $\kappa_{\mathrm{f}}$ & $\mathrm{B}_{\mathrm{f}}$ & $\mathrm{R}^{2}(\%)$ \\
\hline $\mathrm{T} 1$ & 0.42 & 98.7 & 0.42 & 5.57 & 0.11 & 0.40 & 5.15 & 99.9 \\
\hline $\mathrm{T} 2$ & 0.38 & 95.4 & 0.42 & 5.39 & 0.14 & 0.36 & 3.58 & 99.4 \\
\hline $\mathrm{T} 3$ & 0.39 & 98.6 & 0.42 & 5.61 & 0.15 & 0.40 & 5.04 & 99.8 \\
\hline $\mathrm{T} 4$ & 0.41 & 96.0 & 0.42 & 5.51 & 0.19 & 0.40 & 4.89 & 99.4 \\
\hline T5 & 0.39 & 98.3 & 0.43 & 5.78 & 0.15 & 0.39 & 4.60 & 99.7 \\
\hline T6 & 0.35 & 96.1 & 0.47 & 6.75 & 0.04 & 0.38 & 4.49 & 99.0 \\
\hline $\mathrm{T} 7$ & 0.44 & 98.2 & 0.47 & 7.00 & 0.03 & 0.36 & 3.58 & 99.4 \\
\hline
\end{tabular}




\section{Figure Captions}

Figure 1: Typical turbulent flow regions in OCF

Figure 2: The experimental flume setup

Figure 3: Variation of $\frac{\mathrm{dU}^{+}}{\mathrm{dy}^{+}}$vs. $\frac{1}{\mathrm{y}^{+}}$using the derivative method

Figure 4: Determination of $\kappa_{s}$ and $\mathrm{B}_{s}$ for different experiments using scatter method

Figure 5: Streamwise mean velocity distribution in inner scale for different tests

Figure 6: Dimensionless eddy viscosity distribution based on (a) Coles' wake function and (b) Krogstad's wake function

Figure 7: Dimensionless mixing length distributions (outer scaling)

Figure 8: Dimensionless mixing length distributions (inner scaling)

Figure 9: Variation of $\kappa_{1}$ with $\operatorname{Re}_{\theta}$ 


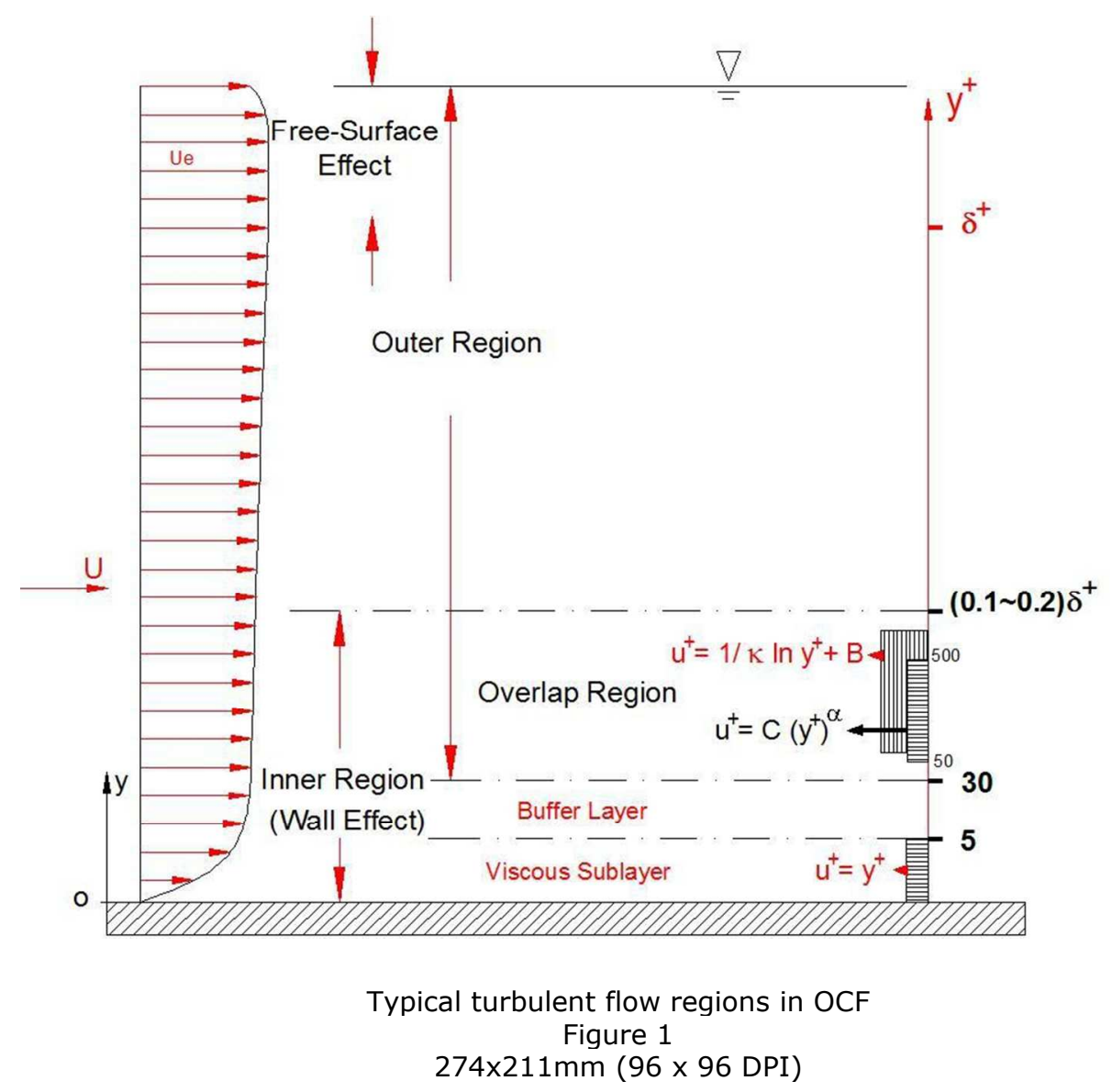

https://mc06.manuscriptcentral.com/cjce-pubs 


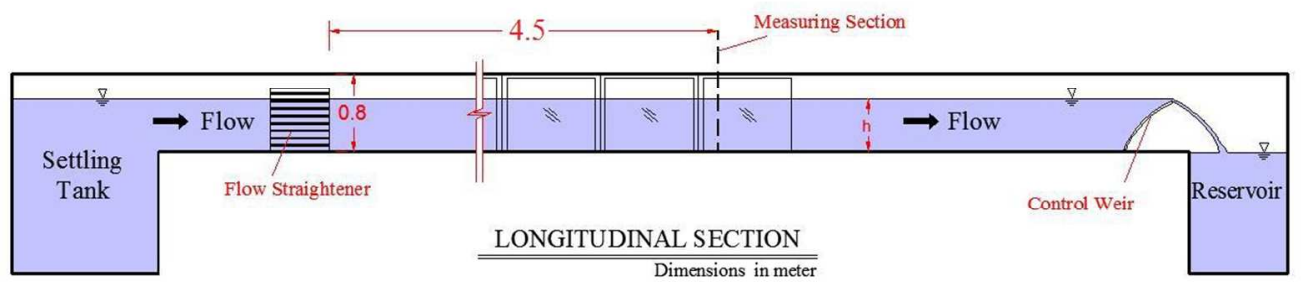

The experimental flume setup

Figure 2

$321 \times 88 \mathrm{~mm}$ (96 x 96 DPI) 


\section{Page 37.0f 43}

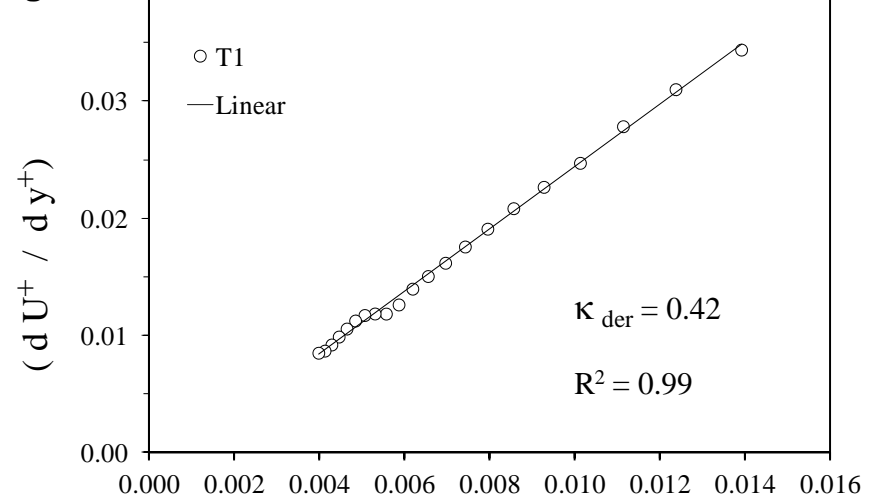
$\begin{array}{lllllllll}0.000 & 0.002 & 0.004 & 0.006 & 0.008 & 0.010 & 0.012 & 0.014 & 0.016\end{array}$ $1 / \mathrm{y}^{+}$

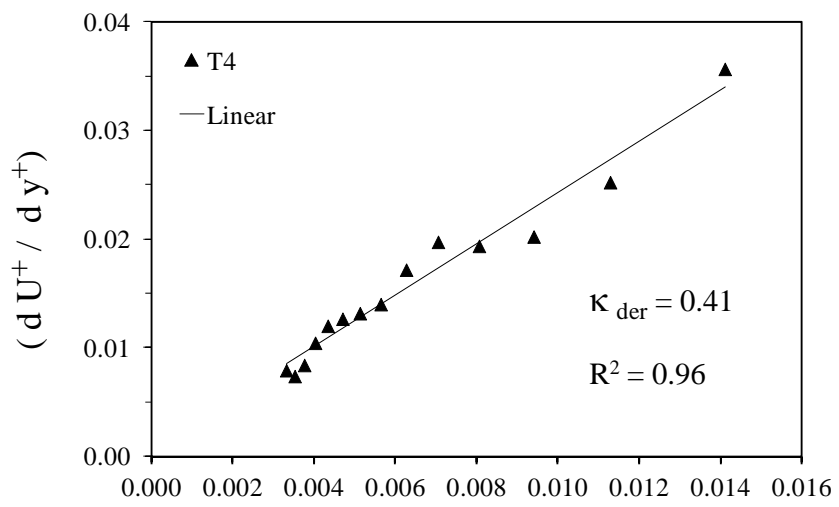

$$
1 / \mathrm{y}^{+}
$$

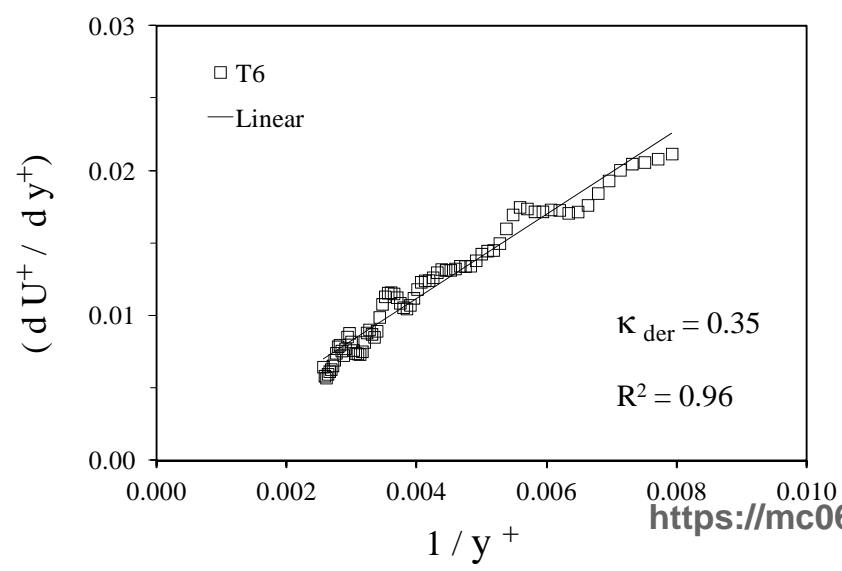

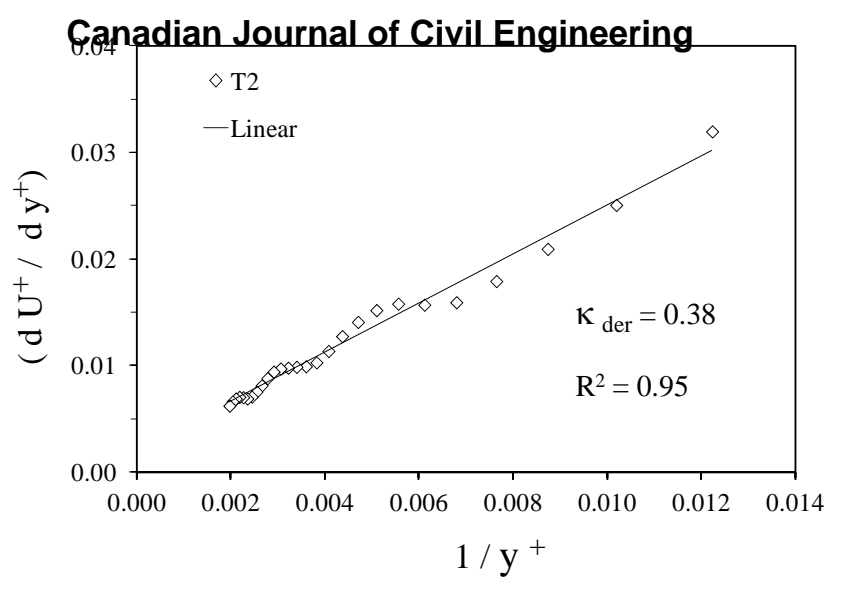
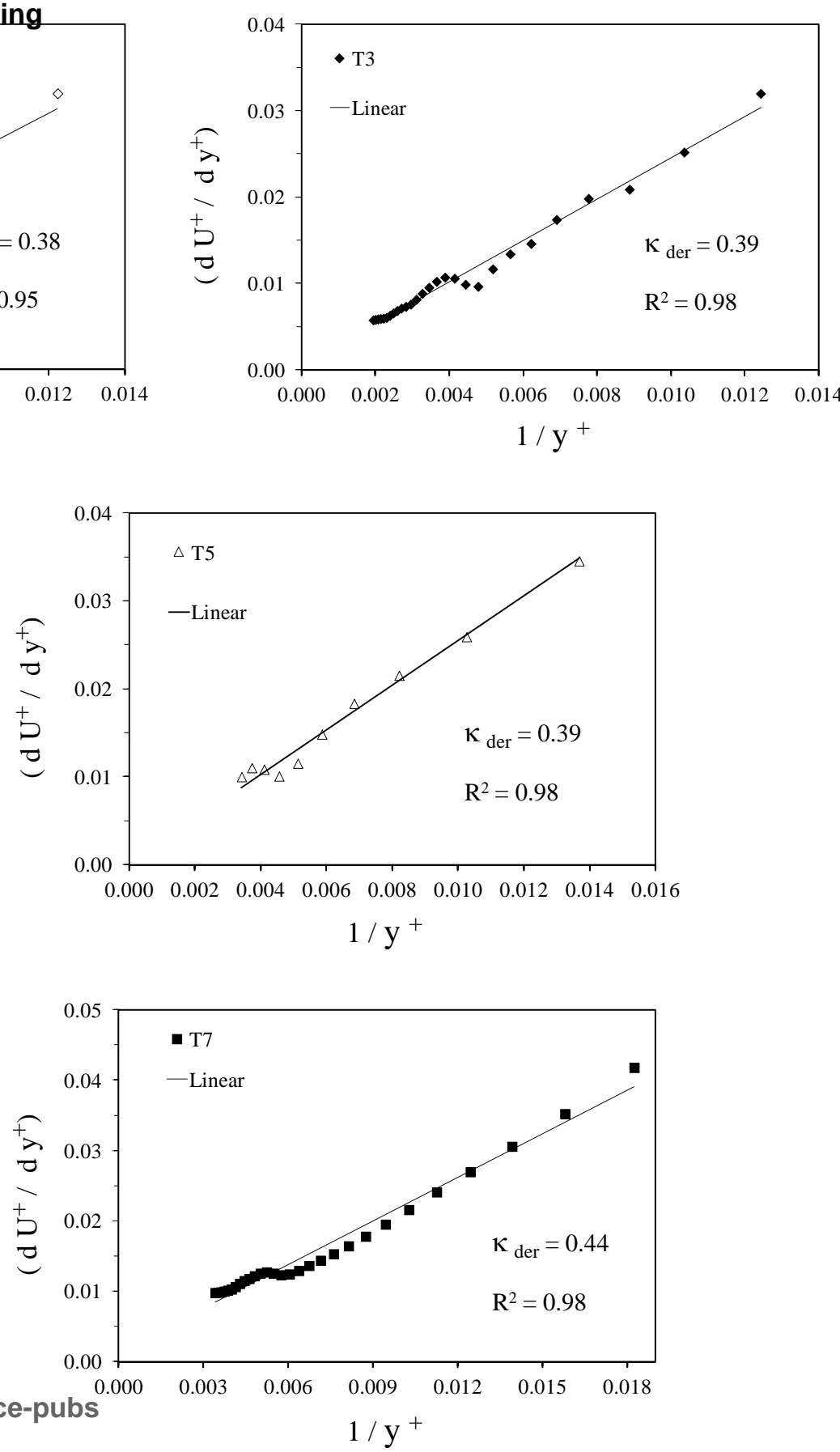


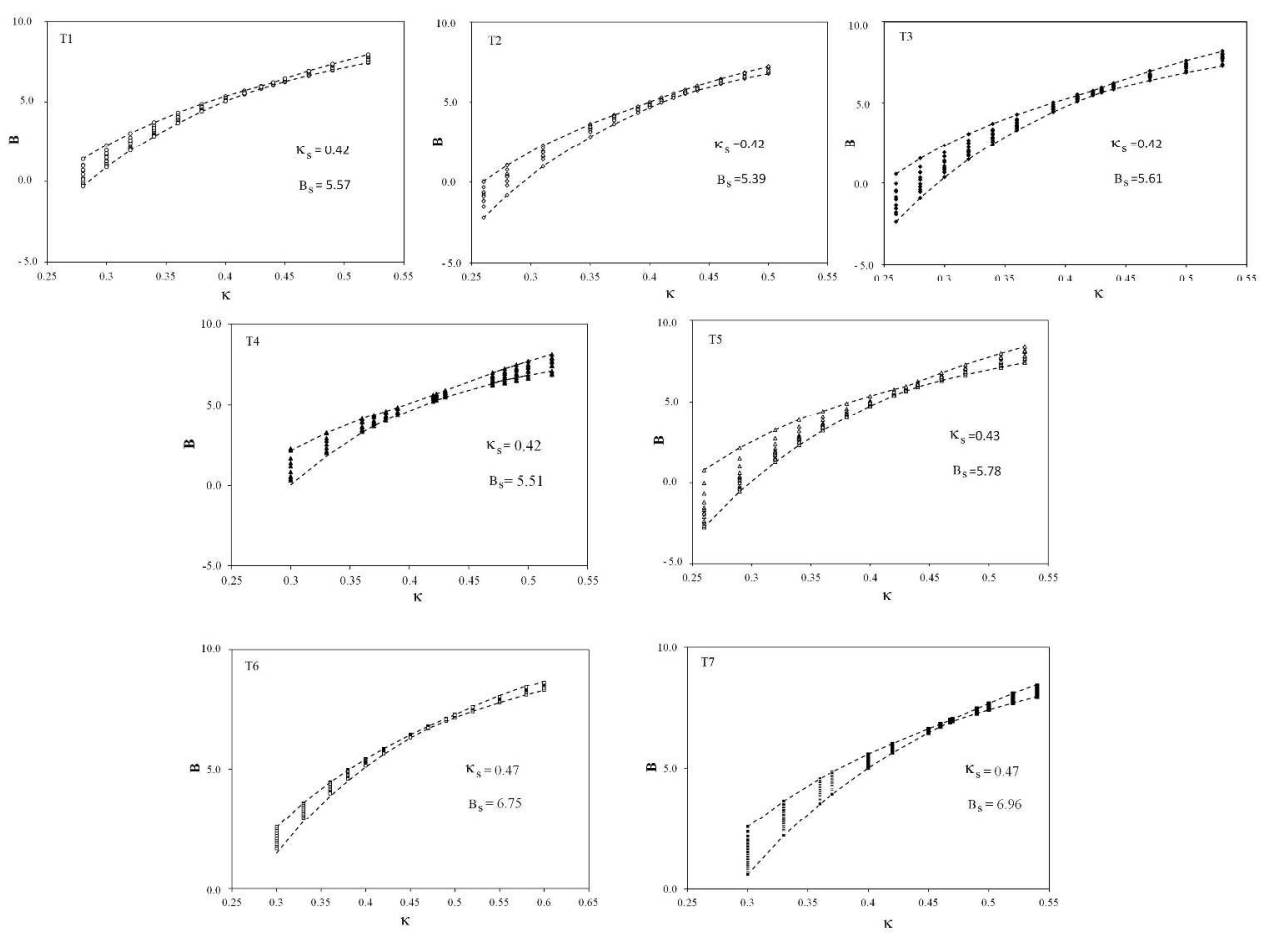

Determining $\mathrm{K}_{\mathrm{s}}$ and $\mathrm{B}_{\mathrm{s}}$ for different experiments using scatter method Figure 4 $969 \times 700 \mathrm{~mm}(96 \times 96 \mathrm{DPI})$ 


\section{Page 39 of 43}
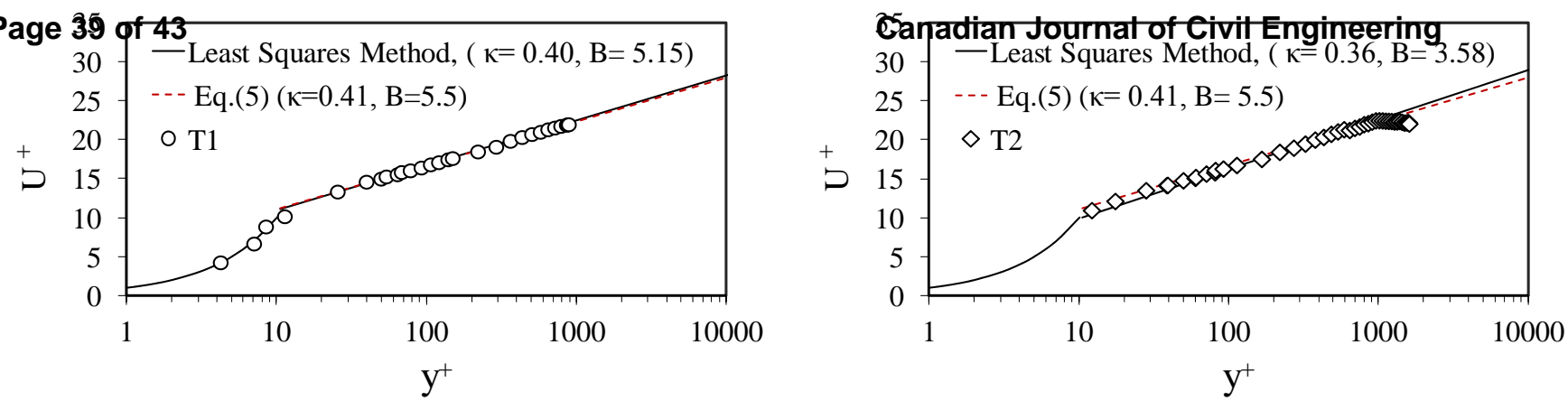
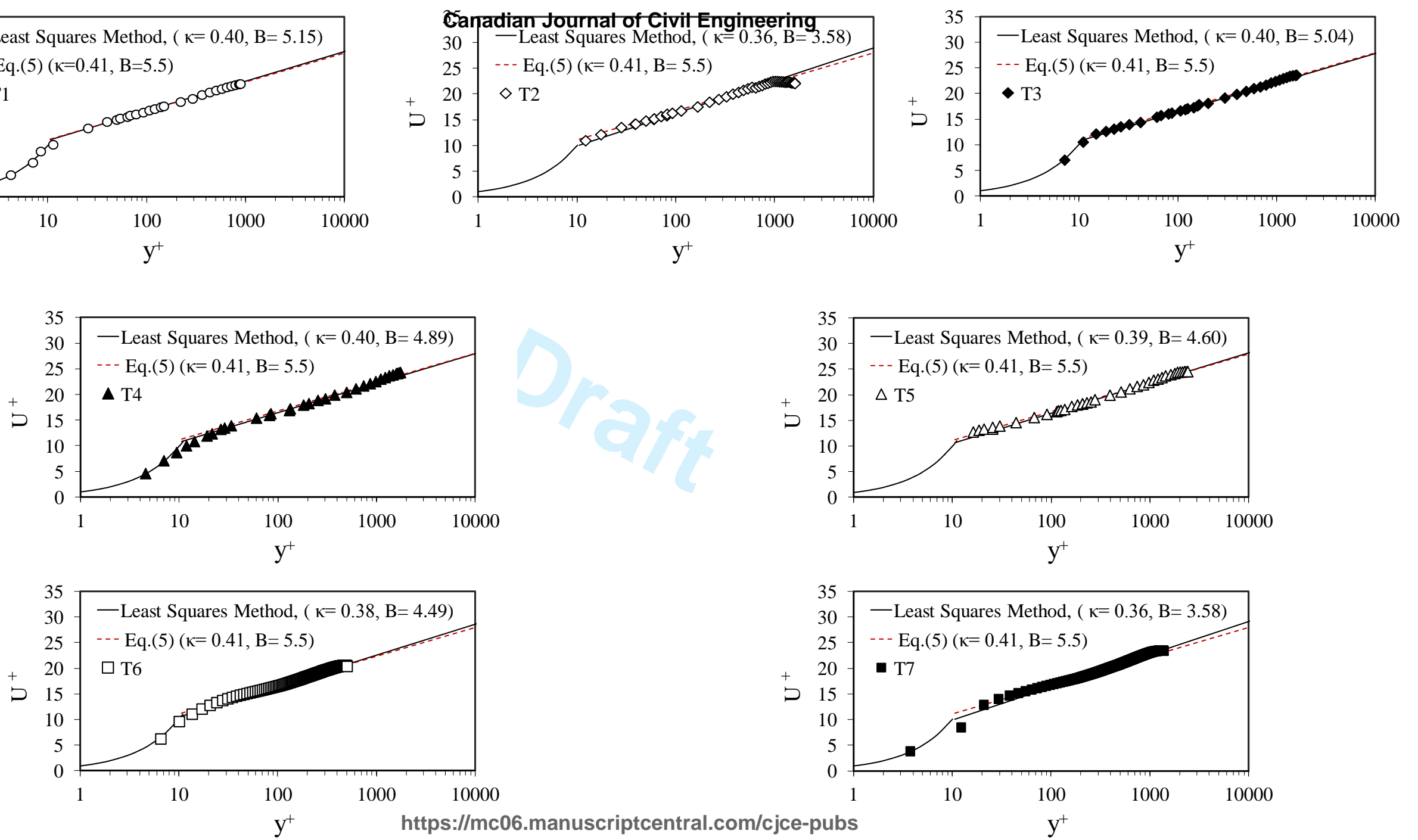

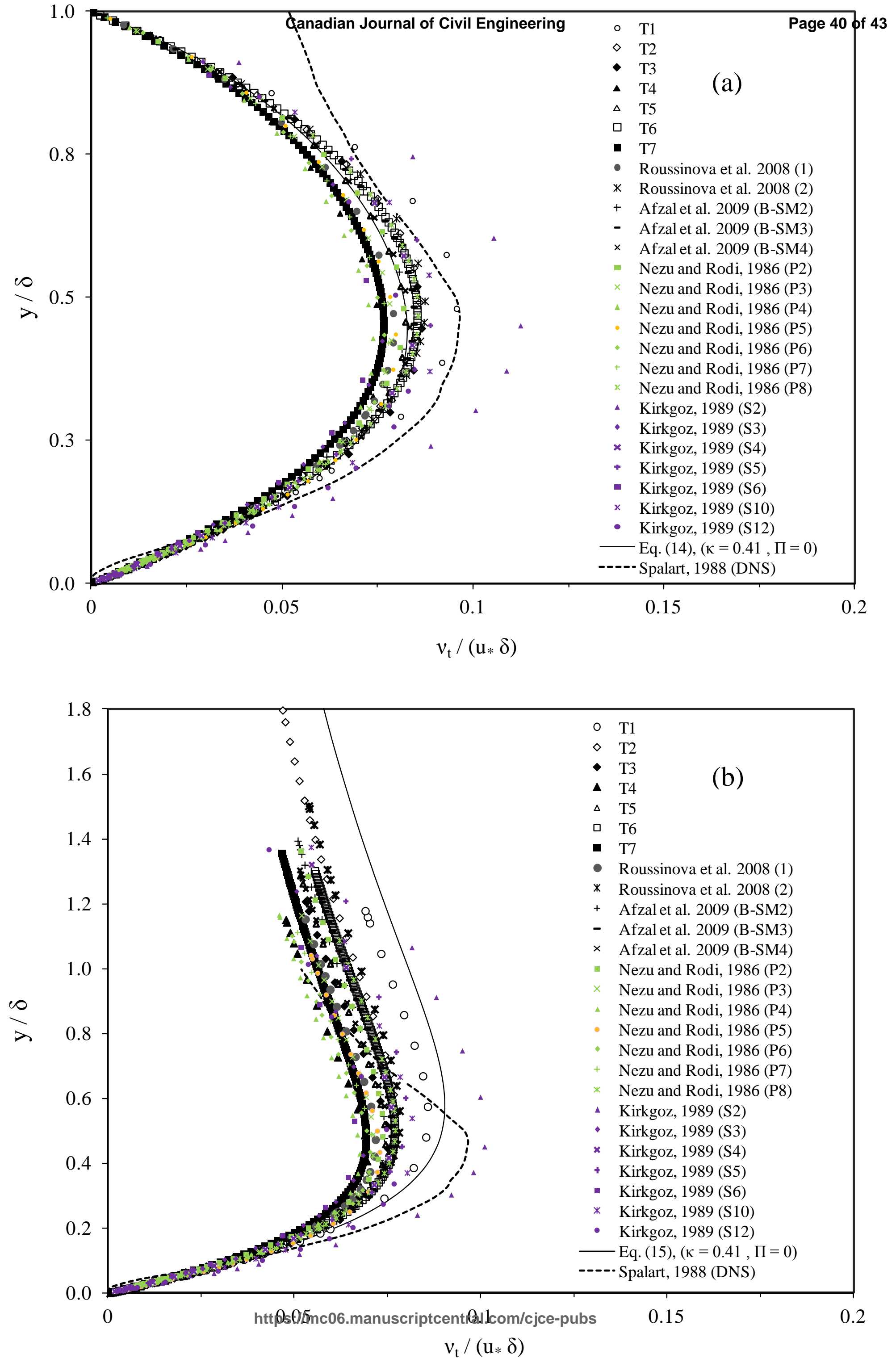


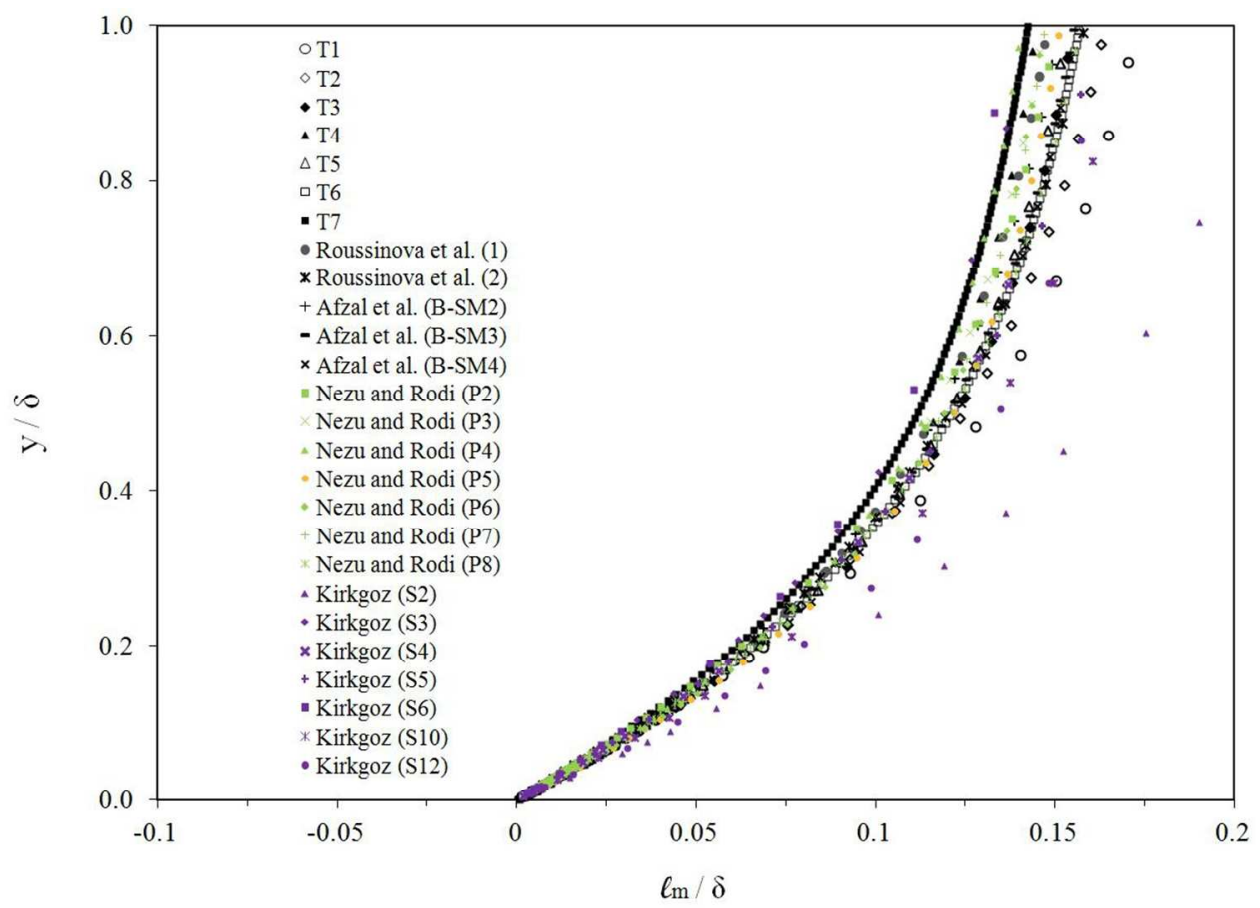

Dimensionless mixing length distributions (outer scaling)

Figure 7

$329 \times 230 \mathrm{~mm}(96 \times 96$ DPI $)$ 


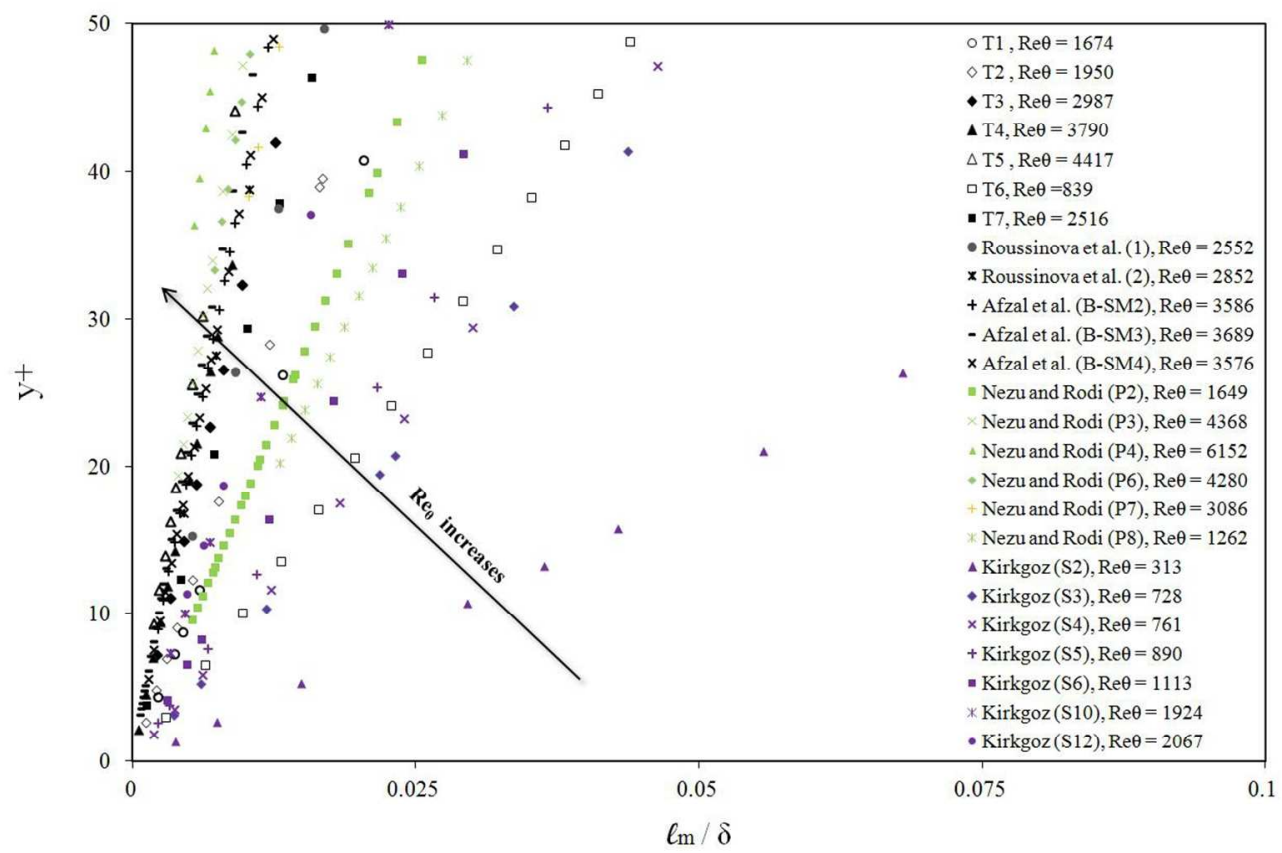

Dimensionless mixing length distributions (inner scaling)

Figure 8

$331 \times 218 \mathrm{~mm}(96 \times 96$ DPI $)$ 


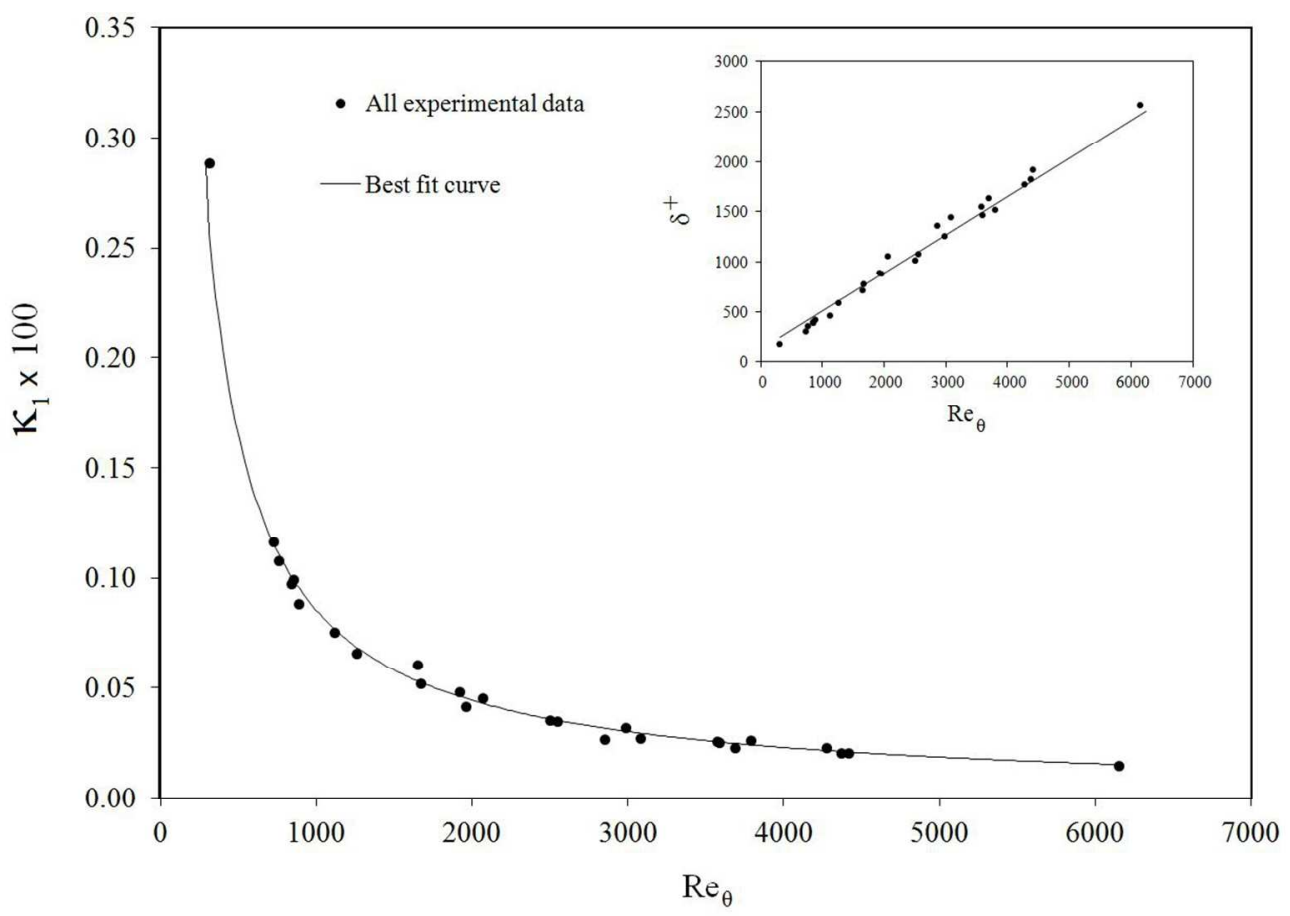

Variation of $\kappa_{1}$ with $\mathrm{Re}_{\theta}$

Figure 9

$327 \times 230 \mathrm{~mm}(96 \times 96$ DPI $)$ 